\title{
Frontiers in therapeutic development of allopregnanolone for Alzheimer's disease and other neurological disorders
}

\author{
Ronald W. Irwin ${ }^{1}$, Christine M. Solinsky ${ }^{2}$ and Roberta Diaz Brinton ${ }^{1,3} *$ \\ Department of Pharmacology and Pharmaceutical Sciences, Pharmaceutical Sciences Center, School of Pharmacy, University of Southern California, \\ Los Angeles, CA, USA \\ ${ }^{2}$ Clinical and Experimental Therapeutics Program, School of Pharmacy, University of Southern California, Los Angeles, CA, USA \\ ${ }^{3}$ Department of Neurology, Keck School of Medicine, University of Southern California, Los Angeles, CA, USA
}

\section{Edited by:}

Giulia Puja, Università degli Studi di Modena e Reggio Emilia, Italy

Reviewed by:

Alexander K. Murashov, East Carolina University, USA

Jie Cui, Roskamp Institute, USA

*Correspondence:

Roberta Diaz Brinton, Department

of Pharmacology and

Pharmaceutical Sciences

Pharmaceutical Sciences Center.

School of Pharmacy, University of

Southern California, 1985 Zonal

Avenue, Los Angeles, CA

90089-9121, USA

e-mail: rbrinton@usc.edu
Allopregnanolone (Allo), a neurosteroid, has emerged as a promising promoter of endogenous regeneration in brain. In a mouse model of Alzheimer's disease, Allo induced neurogenesis, oligodendrogenesis, white matter generation and cholesterol homeostasis while simultaneously reducing $\beta$-amyloid and neuroinflammatory burden. Allo activates signaling pathways and gene expression required for regeneration of neural stem cells and their differentiation into neurons. In parallel, Allo activates systems to sustain cholesterol homeostasis and reduce $\beta$-amyloid generation. To advance Allo into studies for chronic human neurological conditions, we examined translational and clinical parameters: dose, regimen, route, formulation, outcome measures, and safety regulations. A treatment regimen of once per week at sub-sedative doses of Allo was optimal for regeneration and reduction in Alzheimer's pathology. This regimen had a high safety profile following chronic exposure in aged normal and Alzheimer's mice. Formulation of Allo for multiple routes of administration has been developed for both preclinical and clinical testing. Preclinical evidence for therapeutic efficacy of Allo spans multiple neurological diseases including Alzheimer's, Parkinson's, multiple sclerosis, Niemann-Pick, diabetic neuropathy, status epilepticus, and traumatic brain injury. To successfully translate Allo as a therapeutic for multiple neurological disorders, it will be necessary to tailor dose and regimen to the targeted therapeutic mechanisms and disease etiology. Treatment paradigms conducted in accelerated disease models in young animals have a low probability of successful translation to chronic diseases in adult and aged humans. Gender, genetic risks, stage and burden of disease are critical determinants of efficacy. This review focuses on recent advances in development of Allo for Alzheimer's disease (AD) that have the potential to accelerate therapeutic translation for multiple unmet neurological needs.

Keywords: allopregnanolone, Alzheimer's disease, $\beta$-amyloid, neurogenesis, regeneration, cholesterol homeostasis, myelin, treatment regimen

\section{INTRODUCTION}

Neurosteroids, including allopregnanolone (Allo), are a class of neural messengers that regulate multiple processes in brain from ion channel properties to systems regeneration. Therapeutically it is possible to develop neurosteroid analogs to selectively target one action or to use endogenous neurosteroid molecules as systems biology regulators. Each strategy has its strengths and weaknesses. Depending upon the targeted disease and mechanism therein, it is possible to selectively activate a subset of responses or the full complement of potential responses. Therapeutic application of neurosteroids to achieve efficacy in a disease state requires both the understanding of the disease and the systems pharmacology of the neurosteroid (Brinton, 2013).

This review, while largely focused on therapeutic development of Allo for Alzheimer's disease (AD), raises issues that are applicable more broadly to other diseases for which Allo may have therapeutic benefit. Thus the review is structured around a framework of considerations that matter. To substantially advance translational research that is predictive of clinical outcome, we address multiple issues that will ultimately determine translational feasibility and success of Allo across multiple disease conditions. Lastly, most neurodegenerative diseases have no cure although in some instances palliative care extends life but not function. Therapeutics to prevent neurodegenerative disease in populations at risk, delay progression of disease in those affected and restore function in those with late stage disease remain elusive. It is our goal to enable others in the field to advance with greater speed and greater success by considering key aspects of translational research that really matter.

\section{MOLECULAR PHARMACOLOGY MATTERS}

Mechanisms of drug action should be optimally identified, confirmed and characterized in preclinical studies before 
progressing to clinical trials (Becker et al., 2014). Metabolites of progesterone with reduced A-ring steroid structures are potent endogenous agonist modulators of gamma-aminobutyric acid (GABA) type $A$ receptors $\left(G A B A_{A} R s\right)$. The $G A B A_{A} R$ is a ligand-gated ion channel and is primarily associated with inhibition of or fine-tuning of excitatory neurotransmission. The neurosteroid progesterone metabolites that modulate the $\mathrm{GABA}_{\mathrm{A}} \mathrm{R}$ include $3 \alpha$-hydroxy-5$\beta$-pregnan-20-one (pregnanolone); $3 \alpha$-hydroxy-5 $\beta$-pregnan-20-one (allopregnanolone; Allo; $3 \alpha, 5 \beta$-tetrahydroprogesterone) and its 21-hydroxylated derivative: tetrahydro-DOC (THDOC) derived from A-ring reduction of deoxycorticosterone. Of these metabolites, Allo is amongst the most potent endogenous allosteric modulators of the $\mathrm{GABA}_{\mathrm{A}} \mathrm{R}$ (Belelli and Lambert, 2005). Within the mammalian brain, Allo has been shown to modulate anxiety, depression, seizure activity, sedative-hypnotic activity, and the immune system. Adding to this list, we have shown that Allo promotes the neuroregenerative system and modifies the course of neurodegenerative disease.

Neurosteroid molecular structures and their structure-activity relationship with their cognate receptors have undergone eons of co-evolutionary selection. Steroid binding site-containing $\mathrm{GABA}_{\mathrm{A}} \mathrm{Rs}$ could have evolved during early chordate evolution, possibly between the branch points of Cephalochordata (lancelets) and Agnatha (lampreys) (Paul and Purdy, 1992). Much earlier, phylogenetic studies conclude that ligand gated ion channels evolved from protoreceptors in unicellular organisms (Pierobon et al., 2004).

Ionotropic $\mathrm{GABA}_{\mathrm{A}}$ Rs primarily transport chloride and bicarbonate ions. The potencies and efficacies of neurosteroids including Allo depend on the subunit composition of $\mathrm{GABA}_{\mathrm{A}} \mathrm{Rs}$. GABAergic neurotransmission can be fine-tuned by allosteric modulation at $\mathrm{GABA}_{\mathrm{A}} \mathrm{R}$ binding sites for barbiturates, benzodiazepines, anesthetic alcohols, and neurosteroids. At low concentrations, neurosteroids bind to $\mathrm{GABA}_{\mathrm{A}} \mathrm{R}$ at distinct sites to act as positive or negative modulators of $\mathrm{GABA}_{\mathrm{A}} \mathrm{R}$ function (Gee et al., 1987, 1988). Allo is a potent positive allosteric activator of $\mathrm{GABA}_{\mathrm{A}} \mathrm{R}$ channels that at nanomolar concentrations enhances the apparent affinity of GABA for $G_{A B A} R$ and, at micromolar concentrations, can directly activate $\mathrm{GABA}_{\mathrm{A}} \mathrm{R}$ chloride channels. Allo binds to two transmembrane sites of the heteropentameric $\mathrm{GABA}_{\mathrm{A}} \mathrm{R}$ assembled from eight subunit families (Hosie et al., 2006). GABA $\mathrm{R}$ binding sites have the general subunit stoichiometry $2 \alpha: 2 \beta: 1 \gamma$. GABA $\mathrm{R}$ channel complexes that occur at the synaptic cleft have a higher threshold for activation and display phasic conductance. In contrast to synaptic $\mathrm{GABA}_{\mathrm{A}} \mathrm{Rs}$, a subset of extrasynaptic $\mathrm{GABA}_{\mathrm{A}} \mathrm{Rs}$, contain the neurosteroid-sensitive $\delta$ subunit making them pharmacologically distinct and display a tonic conductance pattern (Meldrum and Rogawski, 2007). GABA ${ }_{\mathrm{A}}$ Rs have been identified by electron microscopy in adult hippocampal subgranular zone (SGZ) progenitor cells (Mayo et al., 2005). Surrounding local interneurons that project towards the neurogenic niche and release GABA to adult dentate granule cells are subjected to tonic GABAergic signaling via $\delta$-subunit-containing $\mathrm{GABA}_{\mathrm{A}} \mathrm{Rs}$ (Overstreet Wadiche et al., 2005). Functionally, GABA plays a key role in the generation of spontaneous network activity within immature dentate granule cells (Owens and Kriegstein, 2002; Sipila et al., 2004).

GABAergic signaling likewise controls proliferation of adult progenitor cells within the subventricular zone (SVZ) neurogenic niche (Liu et al., 2005). Progenitor cells in the SVZ coexpress $\mathrm{GABA}_{\mathrm{A}} \mathrm{R} \beta_{2}, \beta_{3}$ receptor subunits, GAD65/67 and GFAP $\delta$ (Dieriks et al., 2013). The expression of GAD65/67 was detected at lower amounts in the SVZ than in the caudate nucleus, and co-labeling was observed with $\mathrm{GABA}_{\mathrm{A}} \mathrm{R} \beta_{2}, \beta_{3}$, and PCNA, suggesting that cells with these markers utilized GABA from early neurogenesis until maturity. $\mathrm{GABA}_{\mathrm{A}} \mathrm{R} \gamma_{2}$ was the most abundant and highly localized to the SVZ. GABA $A_{A}$ s are found throughout the SVZ on all major cell types, however $\mathrm{GABA}_{\mathrm{A}} \mathrm{R} \gamma_{2}$ shows the highest specific expression in the SVZ (Dieriks et al., 2013).

Through a PKC-dependent signaling mechanism, the neurosteroid THDOC selectively potentiated phosphorylation and membrane insertion of the $\alpha_{4} / \delta$ subunit-containing extrasynaptic $\mathrm{GABA}_{\mathrm{A}} \mathrm{R}$ subtypes mediate tonic conductance in the dentate gyrus (Abramian et al., 2014). This effect of THDOC was specific as it did not phosphorylate $\alpha_{5} / \delta$ or KCC2 (Abramian et al., 2014).

The mechanism of action for Allo activated cell cycle gene expression in neural stem cells is mediated by binding to $\mathrm{GABA}_{\mathrm{A}} \mathrm{R}$ to elicit an efflux of chloride and a concomitant influx of calcium that contributes to the induction of cell signaling events which lead to gene transcription of mitotic genes and downregulation of anti-mitotic genes (Brinton, 2013). A rapid rise in intracellular calcium, and subsequent activation of the cell cycle, initiates neurogenesis (Wang et al., 2005; Wang and Brinton, 2008; Brinton, 2013). Upon exogenous administration, a threshold brain concentration of Allo in neural progenitor cells of the neurogenic niches, activates a signaling cascade to trigger cell proliferation (Wang et al., 2005; Wang and Brinton, 2008; Brinton, 2013). Allo in blood and brain is subsequently enzymatically cleared within a timeframe of minutes to hours (Zhu et al., 2001; Timby et al., 2006; Irwin and Brinton, 2014) sufficient to allow regenerative system required for Allo-induced neurogenesis to continue (Brinton, 2013).

Collectively these data provide a window into the richness of the $\mathrm{GABA}_{\mathrm{A}} \mathrm{R}$ system and how Allo modulates the function of these receptors to affect both the excitability of the brain and its regenerative capacity. The unanticipated link of the $\mathrm{GABA}_{\mathrm{A}} \mathrm{R}$ to the regeneration of neural stem/progenitor cells suggests the possibility that other unanticipated and exciting relationships have yet to be identified.

\section{CHOLESTEROL AND THE STEROIDOGENIC SYSTEM MATTER}

The brain must synthesize its own supply of cholesterol from acetyl-CoA independent of peripherally circulating cholesterol. Because all steroids are generated from cholesterol, changes in cholesterol homeostasis will inevitably affect steroidogenesis.

Cholesterol must be delivered to and from cells by lipoproteins which include low-density lipoproteins (LDL) and high-density lipoproteins (HDL). The lipoprotein component ApoE, shuttles cholesterol between cells through the interstitial fluid and therefore regulates the distribution and redistribution of cholesterol to each cell type (Mahley, 1988). Cholesterol is transported within 
the cell via steroidogenic acute regulatory protein (StAR) to the mitochondrial membrane translocator protein (TSPO). TSPO is a mitochondrial rate-limiting control checkpoint regulating cholesterol uptake and thus the synthesis of neuroactive steroids (Rupprecht et al., 2010; Irwin and Brinton, 2014). TSPO forms a cholesterol transport pore in the mitochondrial inner membrane with other proteins that include the StAR, voltage-dependent anion channel protein (VDAC), and adenine nucleotide transporter protein (ANT).

The cholesterol transport pore transports cholesterol to the mitochondrial matrix to be converted into pregnenolone by the cytochrome P450 side-chain cleavage (CYP450scc) enzyme (Liu et al., 2006). Pregnenolone diffuses out of the mitochondrial compartment and is converted in the cytosol to progesterone by $3 \beta$-hydroxysteroid dehydrogenase ( $3 \beta$-HSD). Two enzymes, $5 \alpha-$ reductase $(5 \alpha-\mathrm{R})$ type-I and $5 \alpha$-hydroxysteroid dehydrogenase ( $3 \alpha-\mathrm{HSD})$ are required to synthesize Allo from progesterone (Mellon et al., 2001; Mellon, 2007).

Allo is a reduced metabolite of progesterone, synthesized in the gonads, adrenal cortex, and the central nervous system (Genazzani et al., 2000). In the central and peripheral nervous systems, Allo synthesis occurs primarily in glial cells-astrocytes, oligodendrocytes, and Schwann cells and in many neuronal cell types including neural progenitors (Melcangi et al., 1996; Griffin and Mellon, 2001; Mellon and Vaudry, 2001; Benarroch, 2007).

An expression pattern of progesterone converting enzymes is evident in both hippocampus and cortex. Endogenous Allo production is controlled by the rate-limiting reduction of progesterone to $5 \alpha$-dihydroprogesterone ( $5 \alpha$-DHP) by $5 \alpha-$ R. Progesterone is converted to Allo by the sequential action of $5 \alpha$ $\mathrm{R}$ type-I, to $5 \alpha$-DHP, which is then converted by $3 \alpha$-HSD to form Allo. $5 \alpha$-reductase and $3 \alpha$-hydroxysteroid dehydrogenase are functionally expressed in pluripotent progenitors, neural progenitor cells, and subsets of hippocampal neurons that contain $5 \alpha-\mathrm{R}$ and $3 \alpha-\mathrm{HSD}$ (Melcangi et al., 1996). Subsequently, $3 \alpha-\mathrm{HSD}$ catalyzes conversion of $5 \alpha$-DHP into Allo. Amyloid- $\beta$-binding alcohol dehydrogenase (ABAD) is an enzyme that is associated with mitochondria and facilitates back conversion of Allo to $5 \alpha$ DHP (Yang et al., 2005). Interestingly, anti-depressants, such as fluoxetine, were demonstrated to increase Allo production and although not directly correlated, increased neurogenesis (Malberg et al., 2000; Uzunova et al., 2004, 2006).

Increasing evidence indicates that altered cholesterol homeostasis is linked to neuropathologies including $\mathrm{AD}$ (Schumacher et al., 2004; Mellon et al., 2008; Brinton, 2013). In addition to the mechanism of action whereby Allo induces neurogenesis (Brinton, 2013), Allo regulates cholesterol homeostasis via mechanisms that increases liver-X-receptor (LXR) and pregnane-Xreceptor (PXR; Chen et al., 2011). LXR is a nuclear hormone receptor abundant in the brain, primarily expressed in glial cells and acts as a molecular sensor of cholesterol levels and initiates cholesterol clearance (Whitney et al., 2002; Jakobsson et al., 2012). Loss of either $\operatorname{LXR} \alpha$ or LXR $\beta$ subtype expression exacerbated AD-related pathology in APP/PS1 double transgenic mice (Zelcer et al., 2007). Loss of LXR has been shown to repress cortical neurogenesis particularly during late-embryonic stage development of layer II/III (Fan et al., 2008). LXR activation increases cholesterol efflux through increased ABCA1 and ApoE expression, and prevents overactivation of $\gamma$-secretase and overproduction of A $\beta$ (Whitney et al., 2002; Shenoy et al., 2004; Jiang et al., 2008). LXR activation improved cognitive function in multiple mouse models of amyloidogenesis (Schultz et al., 2000; Whitney et al., 2002; Yang et al., 2006; Xiong et al., 2008; Donkin et al., 2010; Leduc et al., 2010a).

LXRs are recruited to ABCA1 gene promoter regions and ApoE expression to decrease $A \beta$ plaque formation and increase $\mathrm{A} \beta$ clearance (Koldamova et al., 2010) through phagocytosis by microglia (Terwel et al., 2011). Further, LXRs are recruited to the ABCG1 promoter in a ligand-dependent manner to alter epigenetic histone methylation allowing for a relaxed chromatin structure accessible to further gene expression and cholesterol efflux (Jakobsson et al., 2012). LXRs reduce neuroinflammation by inhibition of inflammatory genes (Zelcer et al., 2007). Inflammatory cytokines reach high levels in $\mathrm{AD}$ and when suppressed by LXR activation, enhance the phagocytic activity of microglia and thus A $\beta$ clearance. LXR ligands activate PXR (Riddell et al., 2007). In parallel with an Allo-induced increase in LXR expression in the pre-pathology condition, Allo also increased PXR expression in the pre-pathology 3xTgAD mouse brain (Chen et al., 2011). PXR activation, primarily in neurons, induces cytochrome P450 3A (CYP3A) enzymes including CYP3A4 and CYP3A13 and subsequent cholesterol hydroxylation and activation of organic anion transporters (OATs) for cholesterol extrusion (Sun et al., 2003). In addition to increased LXR and PXR expression, Allo treatment initiated in pre-A $\beta$ pathology 3 -month-old $3 x \operatorname{TgAD}$ mice treated once per week for 6 months increased expression of 3-hydroxy3-methyl-glutaryl-CoA-reductase (HMG-CoA-R) (Chen et al., 2011). Although HMG-CoA-R is the rate-limiting enzyme in cholesterol synthesis, it is also required for production of oxysterols that activate LXR and PXR-mediated gene transcription of cholesterol- and lipid-transport proteins (Leduc et al., 2010b). These data predict that an Allo-induced increase in brain LXR and PXR leads to increased cholesterol efflux, thereby reducing gamma-secretase activation by cholesterol-laden lipid rafts. Allo-stimulated cholesterol efflux is a plausible mechanism for the observed reduction of $27 \mathrm{kD}$ and $56 \mathrm{kD}$ intraneuronal $\mathrm{A} \beta$ oligomers after 6 months of once per week treatment (Chen et al., 2011).

In vivo, brain cholesterol homeostasis and intraneuronal $\mathrm{A} \beta$ are tightly coupled with Allo efficacy (Chen et al., 2011). Deposition of $\mathrm{A} \beta$ in the extracellular compartment disconnected this coupled pathway and led to a loss of Allo efficacy in advanced stages of AD-like pathology in the 3xTgAD model. Allo significantly reduced $A \beta$ generation in hippocampus, cortex, and amygdala, which was paralleled by decreased mitochondrial $\mathrm{ABAD}$ and reduced microglia activation assessed as reduced expression of Iba-1 (Chen et al., 2011). A reduction in ABAD expression lowers mitochondrial dysfunction and simultaneously decreases the amount of Allo that is enzymatically back-converted to its precursor steroid $5 \alpha$ DHP. Allo may stimulate oligodendrocyte progenitor cells in addition to neural progenitor cells and since Allo is a metabolite of progesterone, the observed increases in oligodendrogenesis with progesterone treatment could be due to Allo (Schumacher et al., 2012). The 
myelin marker CNPase, a myelination marker, was increased by once per week Allo, indicating myelinating capabilities in the 3xTgAD mouse model (Chen et al., 2011). In the pre$\mathrm{A} \beta$ pathology cohort, 3-month-old 3xTgAD mice displayed increased expression of liver-X-receptor, pregnane-X-receptor, and 3-hydroxy-3-methyl-glutaryl-CoA-reductase (HMG-CoA$\mathrm{R}$ ), three key proteins that regulate cholesterol homeostasis (Chen et al., 2011). Collectively, Allo is a systems biology regulator that promotes the neuroregenerative system with a simultaneous reduction of $\mathrm{AD}$ pathology in the $3 \mathrm{xTgAD}$ male mouse model.

\section{NEUROSTEROID FORMULATION MATTERS}

The physico-chemical properties of Allo create a challenge for aqueous formulation. Allo's low molecular weight $(318.49 \mathrm{~g} / \mathrm{mol})$ and low number of hydrogen bond donors (one) and acceptors (two) are advantageous brain-targeting properties. However, the $\log \mathrm{P}$-value for Allo, 5.042, poses a solubility challenge for aqueous formulation and thus hinders its use as an orally administered drug (Luchetti et al., 2010). Further challenges exist for enteral absorption of Allo after absorption. To avoid the issues with Allo absorption through the oral route, Allo formulations were developed for parenteral routes of administration.

The physico-chemical properties of SBECD aid in solubilization of drug molecules with low aqueous solubility including Allo. SBECD is a chiral molecule composed of $7 \alpha-\mathrm{D}$ glucopyranose units with a molecular weight of approximately 2163 (molecular formula $\mathrm{C}_{42} \mathrm{H}_{70-} \mathrm{O}_{35} \bullet\left(\mathrm{C}_{4} \mathrm{H}_{8} \mathrm{SO}_{3} \mathrm{Na}\right)_{n} \bullet \mathrm{xH}_{2} \mathrm{O}[n=$ $\sim 6.6$; Figure 1). As does its parent molecule, 2-hydroxypropyl $\beta$-cyclodextrin (HBCD; HPBCD), sulfobutylether $\beta$-cyclodextrin (SBECD) has a primary face diameter of $7.8 \AA$ (or 0.78 nanometers) and a secondary face diameter of $15.3 \AA$ (or 1.53 nanometers). The SBECD chemical structure differs in the side chain hydroxyl groups of HBCD, replaced by sulfo-butyl-ethers thus improving its solubility properties. Multiple SBECD molecules surround each Allo molecule to enable aqueous solubility and enhance delivery properties (Figure 1).

The pharmacokinetics of SBECD revealed a low volume of distribution (Vd) corresponding to extracellular water and a short elimination half-life $\left(t_{1 / 2}\right)$ (Luke et al., 2010). Renal clearance of SBECD was at a rate corresponding to the glomerular filtration rate in all species investigated. A single IV dose of $600 \mathrm{mg} / \mathrm{kg}$ SBECD was administered to male mice. Clearance and $\mathrm{Vd}$ were $20.5 \mathrm{~mL} / \mathrm{min} / \mathrm{kg}$ and $0.98 \mathrm{~L} / \mathrm{kg}$, respectively; the $\mathrm{t}_{1 / 2}$ was $0.6 \mathrm{~h}$ (Luke et al., 2010). In the rabbit, clearance was $5.5 \mathrm{~mL} / \mathrm{min} / \mathrm{kg}, \mathrm{Vd}$ was $0.24 \mathrm{~L} / \mathrm{kg}$, and $\mathrm{t}_{1 / 2}$ was $0.5 \mathrm{~h}$. A single IV dose of $240 \mathrm{mg} / \mathrm{kg}$ SBECD in the dog resulted in a clearance of $4.7 \mathrm{~mL} / \mathrm{min} / \mathrm{kg}, \mathrm{Vd}$ of $0.43 \mathrm{~L} / \mathrm{kg}$, and $\mathrm{t}_{1 / 2}$ of $1.1 \mathrm{~h}$ (Luke et al., 2010). No clinical evidence of toxicity was found in dogs at daily doses up to $1500 \mathrm{mg} / \mathrm{kg}$ (Luke et al., 2010). The no observed adverse event level (NOAEL) for IV SBECD, associated with vacuole uptake of renal proximal tubule epithelium, was set at 80 and $30 \mathrm{mg} / \mathrm{kg}$ in rats and dogs, following bolus injection. The NOAEL associated with foamy or lipid-laden macrophages in the lung was established at $160 \mathrm{mg} / \mathrm{kg}$ in rats and $200 \mathrm{mg} / \mathrm{kg}$ in dogs. SBECD is renally excreted intact and in all studies, no evidence of metabolism of SBECD exists (Luke et al., 2010).
A

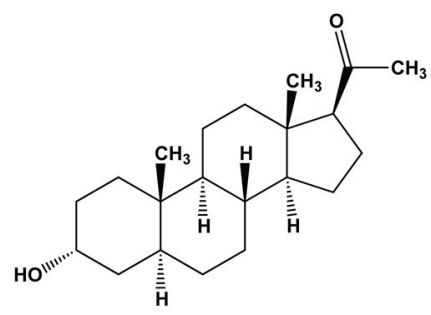

B

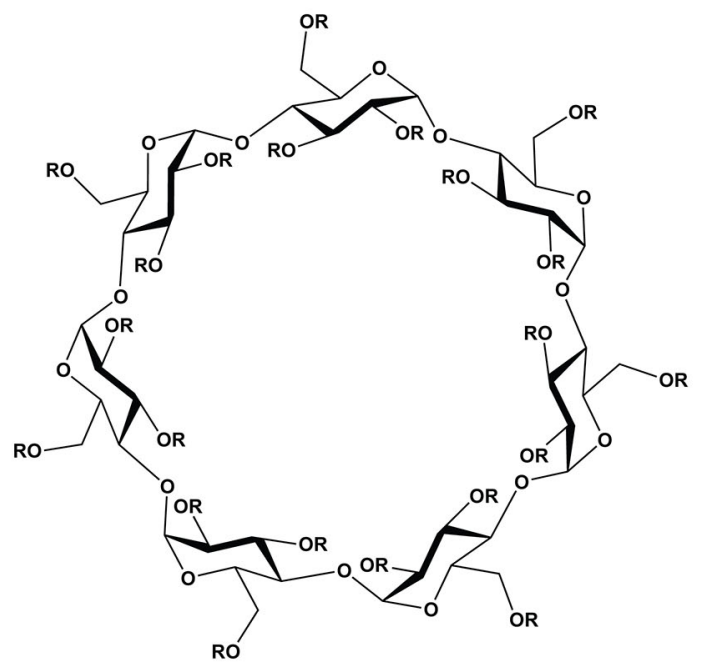

C

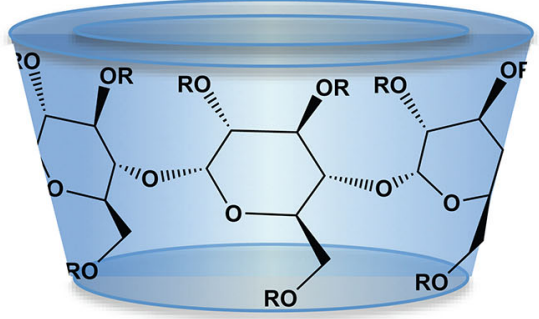

D

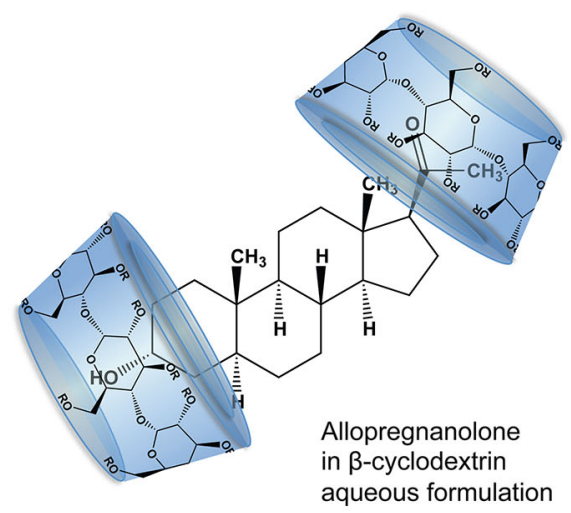

FIGURE 1 | Molecular structure and formulation of allopregnanolone. (A) Chemical structure of allopregnanolone; molecular weight $318.49 \mathrm{~g} / \mathrm{mol}$. (B) Chemical structure of $\beta$-cyclodextrin derivatives, where $\mathrm{R}$ is hydrogen or 2-hydroxypropyl $\left(\mathrm{CH}_{2} \mathrm{CHOHCH}_{3}\right)$ for $\mathrm{HBCD}$ or sulfobutylether $\left(\left(\mathrm{CH}_{2}\right)_{4} \mathrm{SO}_{3}\right.$ $\mathrm{Na}$ ) for SBECD. HBCD has an average molecular weight $\sim 1460 \mathrm{~g} / \mathrm{mol}$, with 0.7-3.15 average degrees of substitution for hydrogen. SBECD molecular weight $\sim 2163 \mathrm{~g} / \mathrm{mol}$ with average degrees of substitution estimated

(Continued) 


\section{FIGURE 1 | Continued}

between 6.3-6.6. (C) The $\beta$-cyclodextrins form three-dimensional cyclic oligosaccharide toroidal structures comprised of 1,4-linked glucopyranose molecules with a hydrophilic outer surface and a hydrophobic inner surface. (D) Allopregnanolone in $\beta$-cyclodextrin formulation to render allopregnanolone water soluble for rapid release in vivo. Two or more molecules of $\beta$-cyclodextrin, represented as toroid-shaped hydrophilic caps, form an inclusion complex with each relatively insoluble Allo molecule.

SBECD is approved for use in marketed drug products including intravenous voriconazole, amiodarone, ziprasidone, aripiprazole, and maropitant (Luke et al., 2010). Human exposure data based on Pfizer's regulatory submission were derived from four clinical studies where IV SBECD was administered (Luke et al., 2010). A total of 49 healthy male volunteers received IV infusions of SBECD alone. SBECD doses between 25 and $200 \mathrm{mg} / \mathrm{kg} /$ day were used to assess the safety and pharmacokinetics. In patients with renal problems, steady-state conditions indicated that even with daily hemodialysis, SBECD was effectively eliminated during $6 \mathrm{~h}$ of renal replacement therapy (Hafner et al., 2010). In older patients such as those in $\mathrm{AD}$ clinical trials, renal function is an important consideration when selecting a formulation and monitoring its safety and clearance. SBECD is relatively safe and with intermittent exposure is unlikely to accumulate based on human pharmacokinetic studies.

The therapeutic dose of Allo for humans is likely within the dose-range explored in previous clinical studies with IV Allo 0.05$0.9 \mathrm{mg} / \mathrm{kg}$ (Timby et al., 2006; van Broekhoven et al., 2007; Grant et al., 2008; Kask et al., 2008, 2009). With a 30\% SBECD formulation of Allo for example, the amount of SBECD would be less than the NOAEL with species allometric scaling. Hypothetically, IV Allo at $0.9 \mathrm{mg} / \mathrm{kg}$ or $6.3 \mathrm{mg} / 70 \mathrm{~kg}$ human, in a $5 \mathrm{mg} / \mathrm{ml}$ soluble formulation of 30\% SBECD, would amount to $378 \mathrm{mg}$ of SBECD or $5.4 \mathrm{mg} / \mathrm{kg}$. Citing the NOAEL of $160 \mathrm{mg} / \mathrm{kg}$ in rats (Luke et al., 2010), allometric scaling to humans would approximate to
$27 \mathrm{mg} / \mathrm{kg}$, whereas the dose in this hypothetical tolerable dose situation would be approximately $5.4 \mathrm{mg} / \mathrm{kg}$ SBECD to deliver $0.9 \mathrm{mg} / \mathrm{kg}$ Allo.

The complexation ratio of the combination of the excipient (SBECD) and the neurosteroid (Allo) has limitations based on solubility properties (Figure 1). The complexation ratio of Allo with cyclodextrins such as SBECD is a major determinant of release of Allo into the blood and brain (Figure 2). To develop formulations with clinical utility, we tested multiple Allo/SBECD complexation ratios on behavior in adult rats (Irwin et al., 2013). The optimal Allo:SBECD formulation (molar ratio of 5.89) was fully soluble and bioavailable as indicated by rapidly induced and prolonged sedation at the maximally tolerated dose for sedation $8 \mathrm{mg} / \mathrm{kg}$ subcutaneous in rats. When the ratio was increased (molar ratio of 23.56), the rate of Allo release into the brain was reduced as indicated by a lack of sedation (Figure 2B). Likewise, when the ratio was decreased (molar ratio of 1.47) relative to optimal, the rate of Allo release into the brain was also reduced (Figure 2B). The volume of soluble Allo administered in the saturated suspension formulation is limited when dosing $8 \mathrm{mg} / \mathrm{kg}$ to rats and results in mild sedative effects likely due to the relatively small fully soluble fraction giving the suspension formulation dual properties. Based on these data, it was postulated that a small but fully soluble fraction was rapidly delivered to the brain at a low dose followed by a slowly absorbed suspension fraction that does not possess the release rate required for sedation at the $8 \mathrm{mg} / \mathrm{kg}$ dose level (Irwin et al., 2013).

Efforts to synthesize water-soluble analogs of neurosteroids, including Allo and progesterone have been made with the goal to maintain structure-activity relationships (MacNevin et al., 2009). Excipients with prior regulatory approval are most desirable for formulations since they have undergone extensive toxicology testing and are more likely to gain regulatory acceptance when formulated with new active ingredients required to undergo their own extensive quality and safety assessments.
A

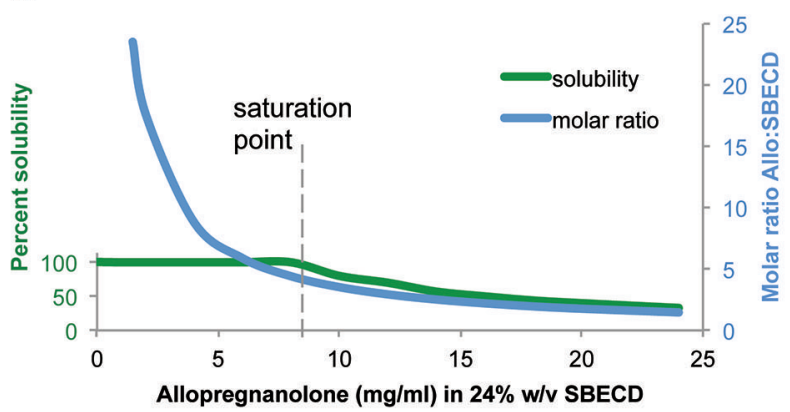

FIGURE 2 | Formulation of allopregnanolone matters. (A) Percent solubility of allopregnanolone (Allo) in $24 \% \mathrm{w} / \mathrm{v}$ SBECD. Allo reached an optimal formulation of $6: 1$ at Allo $6 \mathrm{mg} / \mathrm{ml}$ in $24 \%$ SBECD. Solubility began to decline, observed by precipitation, when Allo concentration was between $8-10 \mathrm{mg} / \mathrm{ml}$ coinciding with a molar ratio of between 4-5 SBECD molecules per Allo molecule in water at room temperature without $\mathrm{pH}$ adjustment. (B) Motor control/sedation at 25 min after subcutaneous Allo $8 \mathrm{mg} / \mathrm{kg}$ to male rats measured by balance beam task on a five point scale where 4 = reaches platform; 3 = takes steps; 2 = all paws on top; $1=$ clasp;
B

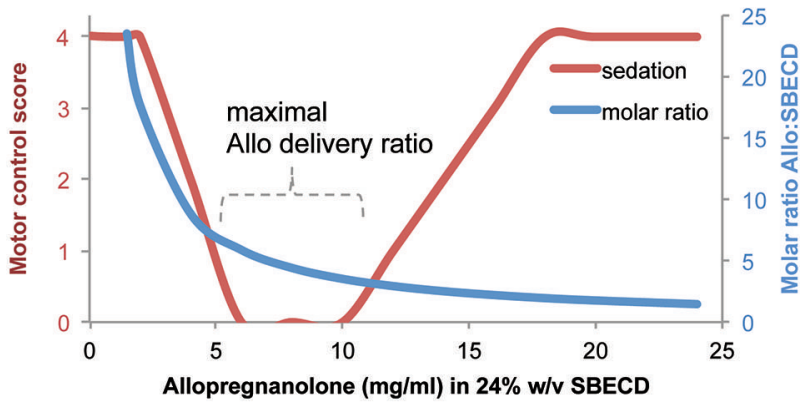

0 = fall off beam (Irwin et al., 2013). Molar ratio was plotted to illustrate relationship between Allo-induced loss of motor control and SBECD:Allo complexation ratio. Via subcutaneous injection, soluble formulations with SBECD:Allo between 7:1 and 3:1 maximally delivered Allo to systemic circulation resulting in rapid brain uptake observed by altered motor control. The cyclodextrin vehicle SBECD does not cross the blood brain barrier but facilitates Allo release to steroid carrier proteins in blood. The motor control/sedation test was used as a safety biomarker of maximally tolerable Allo target engagement in brain. 


\section{DOSE AND ROUTE OF ADMINISTRATION MATTER}

For therapeutic use of Allo, it is imperative to determine the optimal dose, formulation, and dosing regimen (Brinton, 2013). The dose of Allo matters within the context of the targeted biological system. Safety and efficacy must be balanced to avoid unnecessary overexposure and remain consistent with a balanced neuroendocrine system (Figure 3). For most efficacy outcomes, Allo, like other neurosteroids, has an inverted U-shaped dose response profile-too high or too low of an Allo dose leads to suboptimal responses (Wang et al., 2005). Allo induces neurogenesis through potentiation of $\mathrm{GABA}_{\mathrm{A}} \mathrm{R}$ chloride channels in neural progenitor cells in a dose-dependent manner: 10, 100, and $250 \mathrm{nM}$ doses were efficacious whereas neurogenic efficacy diminished at higher doses (Wang et al., 2005; Wang and Brinton, 2008).

In vivo, we have shown that both dose and route matter to determine the therapeutic range and tolerability of Allo (Irwin et al., 2011; Irwin and Brinton, 2014). In our previous in vivo studies, subcutaneous Allo was administered in the range of 1$20 \mathrm{mg} / \mathrm{kg}$ to mice (Wang et al., 2010). The dose of Allo $10 \mathrm{mg} / \mathrm{kg}$ via subcutaneous route was selected for subsequent studies based on hippocampal BrdU incorporation as an indicator of neurogenesis (Wang et al., 2010). Subcutaneous Allo injections were also shown to be effective in a mouse model of Niemann-Pick Type C (NPC; Griffin et al., 2004) and in addition to increased myelin formation and decreased demyelination, the efficacy of Allo was partly due to a reduction of oxidative stress (Zampieri et al., 2009).

For human translation, subcutaneous or intramuscular injections are advantageous due to ease of administration, patient compliance, and tolerability. Allo pharmacokinetics and pharmacodynamics were determined by a combination of brain and blood levels associated with degree of sedation and amount of hippocampal neurogenesis (Irwin et al., 2013). Our recent studies found that sedation following subcutaneously administered Allo in the rat was more variable than the intramuscularly administered response (Irwin et al., 2013). Our analyses indicated that an intramuscular dose was approximately twice as potent at inducing sedation as subcutaneous delivered in a rapid release formulation (Irwin et al., 2013). The no-observable-adverseeffect or subsedative dose level was finely tuned by conducting a series of rat sedation studies within the dose range of our mouse efficacy studies. Subsedative doses were determined to optimally increase markers of neurogenesis including significant increases in BrdU labeled nuclei in the hippocampus (Irwin et al., 2013). Pharmacokinetic studies often begin with the intravenous route to provide maximal bioavailability and inform further studies by alternative routes. An intravenous Allo no-observable-adverseeffect dose of $0.5 \mathrm{mg} / \mathrm{kg}$ in mice or $0.2 \mathrm{mg} / \mathrm{kg}$ to rats is predicted by allometric species conversion calculations to be equivalent to a human intravenous dose of approximately $0.42 \mathrm{mg} / \mathrm{kg}$ or $\sim 3 \mathrm{mg}$ for a $70 \mathrm{~kg}$ adult. Allo has been tested in preclinical models via multiple routes of administration to establish safe dosage ranges for each route.

When selecting an Allo dose or reviewing the available literature (Irwin et al., 2011; Irwin and Brinton, 2014), it is important to compare and contrast the treatment methods and animal models within each study. Evaluation of therapeutic potential requires a deep understanding of the dose and route of administration that will influence pharmacokinetic and pharmacodynamic outcomes.

\section{TREATMENT REGIMEN MATTERS ALZHEIMER'S DISEASE}

Neurogenesis occurs over the course of hours in the case of transitioning through the cell cycle, to months in the case of full integration into hippocampal circuitry and networks (Brinton, 2013). Activating both regenerative and repair systems to maximize therapeutic benefit in the ageing or degenerating brain requires dual assessment of pathology and proliferation simultaneously.

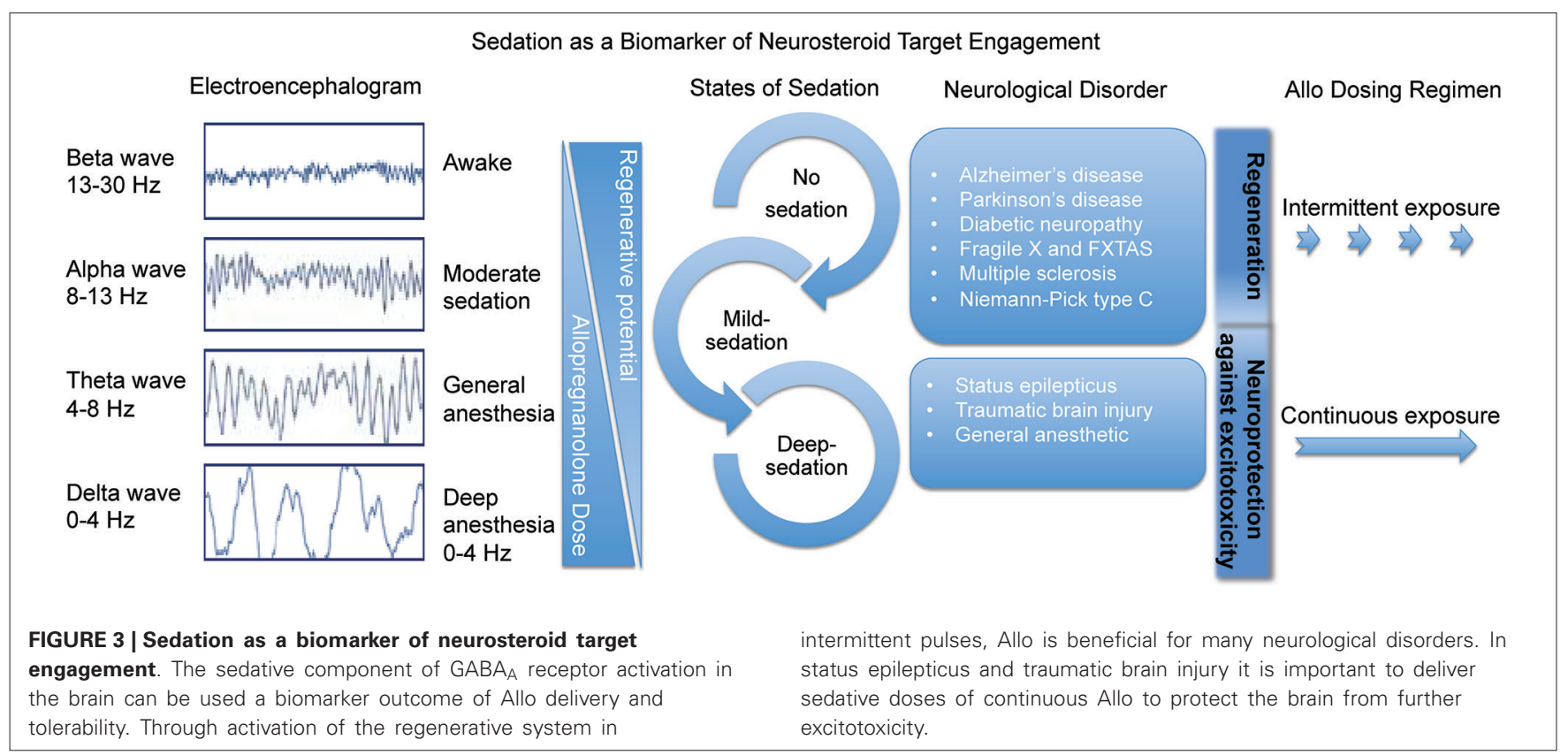


Further, multiple dosing regimens should be tested in order to conclude that regimen does matter and to determine an optimal therapeutic regimen. Our studies followed this plan to determine that Allo treatment regimen matters, testing administration of Allo every day, every other day, every week, and every month. Results of these studies indicate that a once per week treatment regimen with a single dose of Allo $(10 \mathrm{mg} / \mathrm{kg})$ was optimal to promote neurogenesis while also activating systems that reduced Alzheimer disease pathology (Chen et al., 2011).

We previously demonstrated that Allo induces neural stem cell cycle gene expression (Wang et al., 2005) and induces key regulators of cholesterol homeostasis (Chen et al., 2011) to provide mechanistic plausibility for its therapeutic efficacy to promote neurogenesis and cognitive function while reducing $\mathrm{AD}$ pathology following intermittent dosing. Allo promotes neurogenesis (Wang et al., 2005, 2010), recovery of learning and memory function (Wang et al., 2010; Singh et al., 2012), and reduction of AD pathology burden (Chen et al., 2011) in the 3xTgAD mouse model. We have demonstrated that regeneration is achieved with either once per month or once per week regimen of Allo (Chen et al., 2011). In the same mouse model, the reduction of $\mathrm{AD}$ pathology was achieved with once per week or every other day regimens (Chen et al., 2011; Irwin et al., 2011; Brinton, 2013). A combination of regeneration and reduction of pathology was achievable with an intermittent, once per week, Allo treatment regimen (Figure 3 ).

Intermittent Allo treatment regimens have shown benefit in a spectrum of preclinical neurodegenerative disease models including NPC (Griffin et al., 2004), diabetic neuropathy (Leonelli et al., 2007), peripheral nerve injury (Meyer et al., 2008), multiple sclerosis (Noorbakhsh et al., 2011), and Parkinson's disease (Adeosun et al., 2012). Frequent or constant exposure to Allo is not better for regenerative processes although more often than once per week improved reduction of $\beta$-amyloid-burden diseasemodifying effects (Chen et al., 2011). By contrast, a constant infusion treatment regimen over the course of months was antiregenerative and resulted in adverse outcomes (Bengtsson et al., 2012, 2013; Irwin and Brinton, 2014). Unnecessary constant infusion of Allo is not biologically relevant and therefore should not be a therapeutic option for neurological disorders other than epileptic seizure and traumatic injury (Figure 3).

Allo concentrations in blood and brain are stress responsive and serve to restore normal GABAergic and hypothalamicpituitary-adrenal (HPA) function following stress (Crowley and Girdler, 2014). An elevation of neurosteroids in response to stress is an adaptive anxiolytic response in acute stress situations. However, during chronic stress and depression, a condition collectively termed as allostatic load, system-wide decreases in brain and plasma neurosteroid concentrations occur and overall the response to acute stressors becomes dysfunctional (Genazzani et al., 1998; Bernardi et al., 2000; Dong et al., 2001; di Michele et al., 2003). Thus, a disruption in the biologic stress response system can exacerbate stress response disorders (Crowley and Girdler, 2014). Like the regenerative system, the stress response system requires a recovery period. Because of the temporal constraints of the regenerative system in brain, other regenerative factors are likely to have greater efficacy when administered with intermittent treatment regimens. In contrast, those emergency neurological conditions including traumatic brain injury and status epilepticus (Rogawski et al., 2013; Zolkowska et al., 2013) with intense seizure susceptibility and immediate risk of massive glutamate excitotoxicity and hypoxia require constant infusion regimens to dampen neuroexcitation to protect the central nervous system. We postulate that during the early stages of $\mathrm{AD}$ pathology development, administering pulsatile doses of Allo is therapeutically relevant to biological systems including the stress response system and the neuroregenerative system. Safe and tolerable Allo dose exposure serves as a neuroendocrine signal to initiate neuroregeneration.

Based on the therapeutic efficacy of Allo in a preclinical $\mathrm{AD}$ mouse model and in normal aged mice, we predict that Allo has potential therapeutic benefit in humans to delay progression in persons with familial early-onset $\mathrm{AD}$ and to prevent and delay disease in late onset $\mathrm{AD}$. In these populations, Allo could be an effective therapy to promote the regenerative potential and myelination capacity of the brain to prevent or delay progression of mild cognitive impairment to clinically diagnosed $\mathrm{AD}$. In summary, targeting a unique mechanism of action, Allo promotes the innate regenerative capability of the brain by increasing the number and survival of newly generated neurons. However, for therapeutic efficacy of Allo, it is imperative to determine the appropriate dosing regimen specific to each indication.

\section{SAFETY AND TOLERABILITY MATTER}

Earlier we reviewed the existing preclinical and clinical safety data in support of Allo therapeutic development (Irwin et al., 2011; Irwin and Brinton, 2014). Allo is a blood brain barrier penetrant molecule with previous safety data in humans (Timby et al., 2006; van Broekhoven et al., 2007; Grant et al., 2008; Kask et al., 2008, 2009). A cumulative dose of $0.9 \mathrm{mg} / \mathrm{kg}$ or approximately $6 \mathrm{mg}$ for a $70 \mathrm{~kg}$ human, was administered to 9 men and 9 women with mean ages of 24.6 and 21.8 years respectively. Allo was generally well-tolerated with peak blood levels of $100 \mathrm{nM}$ for women and $150 \mathrm{nM}$ for men (van Broekhoven et al., 2007). Self-reported sedation and drowsiness were followed by and recovery followed the metabolic half-life of circulating Allo which was eliminated within hours (van Broekhoven et al., 2007). Physiological exposure to Allo is highest in the third trimester of pregnancy when levels reach $50 \mathrm{ng} / \mathrm{ml}$ or $157 \mathrm{nM}$ (Luisi et al., 2000).

In human Phase 1 studies for $\mathrm{AD}$, fully bioavailable intravenous injection of Allo in a dose escalation design will reach a limit with mild sedation to establish the maximally tolerated dose following intravenous administration. Currently, the upper physiological Allo blood concentration during the third trimester of pregnancy sets the safe exposure boundary until chronic toxicology studies conducted under Good Laboratory Practice (GLP) standards in rodent and non-rodent species are completed. Regulatory agencies require extensive and pivotal toxicology studies prior to large clinical trials and Allo drug product approval. These studies are necessary to demonstrate the safety within a specified dosage range and duration of exposure. GLP is a standardized quality system of management controls to ensure that in non-clinical laboratory studies the 
integrity of drug products such as Allo are planned, performed, monitored, recorded, reported and archived in a uniform, consistent, reliable, reproducible manner. GLP studies include extensive non-clinical safety tests that include specification of physicochemical properties generated under Good Manufacturing Practices (cGMP) and acute dose-range finding studies to chronic toxicity tests in rodents and non-rodent species to meet or exceed the duration of the clinical trial (Steinmetz and Spack, 2009).

In the US, all preclinical safety studies that contain investigational active pharmaceutical ingredients should seek regulatory guidance and oversight by the FDA. Regulatory agencies of many countries follow the International Conference on Harmonization guidelines. Pre-meeting with the regulatory agency will greatly improve important communication and a focused track to develop the Investigational New Drug (IND) application. IND approval in the US, or its equivalent application review process in other countries, must be obtained prior to initiation of standard clinical trials to establish safety and tolerability (Phase I) and efficacy (Phase II). Application for compassionate use IND requirements may be abbreviated for certain life threatening disease conditions outside of clinical trials that require emergency care decisions for expanded use discussed between physicians and regulatory agencies.

Safety reporting rules and timelines must also be maintained and monitored throughout the trial. In cases where existing preclinical toxicology and human exposure data are available, or highest physiological exposure has been studied, as is the case with Allo (Luisi et al., 2000), regulatory agencies may consider the active pharmaceutical ingredient to be sufficiently safe at a specified dosage range to move forward with safety and efficacy studies in humans. The entire process of drug development including time investment and funding must be kept in mind when planning viable therapeutic strategies for Allo. Along the Allo drug development timeline, leverage points are gained such as completion of chronic toxicology studies and should be shared when permissible to accelerate expanded access for neurological diseases similar dose, route, and treatment regimens overlap.

Toxicology studies define the safe exposure limits in animals and the outcomes are then extrapolated to predict maximally safe and tolerable exposure limits for initial human trials. Diseasemodifying claims are stringently reviewed and may require additional safety studies beyond the standard toxicology battery. For example, recent $\mathrm{AD}$ beta-amyloid modifying therapies have shown in clinical studies to increase the risk for vascular edema, detected by magnetic resonance imaging (Salloway et al., 2009; Sperling et al., 2011b, 2012). Increased risk for microbleeds prompted regulatory agencies to require new safety measures for candidate $\mathrm{AD}$ drugs in pre-clinical stages. Drug candidates that claim to modify amyloidogenic mechanisms may require additional preclinical assessment of the associated risk for cerebral microhemorrhages in an appropriate animal model. Currently several AD mouse models are considered appropriate however these studies are costly in terms of time and money. Microhemorrhage risk assessment studies require cohorts of $\sim 2$ year old transgenic AD mice (Pfeifer et al., 2002; Racke et al., 2005; Demattos et al., 2012).
At the stage of dose range finding in rodents and nonrodents, tolerability predictions can be made ranging from the no-observed-adverse-effect level up to the maximally tolerated dose. For neurological disorders, a well-known biomarker of Allo target engagement and tolerability is sedation (Damianisch et al., 2001). Inhibition of the tuberomammillary nucleus has a key role in the sedative or sleep-inducing response to anesthetics that act on the $\mathrm{GABA}_{\mathrm{A}} \mathrm{R}$ (Nelson et al., 2002). The sedation response to Allo can be objectively measured by detection of saccadic eye movement or brain activity via electroencephalogram (Figure 3; van Broekhoven et al., 2007) as was done with benzodiazepine drug development (Van Steveninck et al., 1993). Sedation level due to neurosteroids can also be subjectively determined by clinical observation and by visual analog scales (van Broekhoven et al., 2007). Typically, a combination of objective and subjective measures of sedation are used to assess tolerability. Allo induces dose-related sleep changes including a reduced sleep onset latency and increased pre-rapid-eyemovement sleep (Lancel, 1999). Allo has a safer tolerance profile than most $\mathrm{GABA}_{\mathrm{A}} \mathrm{R}$ agonists including benzodiazepine hypnotics (Damianisch et al., 2001).

A neural network comprised of at least three discrete brain regions promotes sedation non-rapid eye movement sleep. GABAergic neurons of which Allo targets are in the ventrolateral preoptic nucleus are under tonic inhibition from noradrenergic neurons of the locus coeruleus. Inhibition of locus coeruleus neurons results in activation of the ventrolateral preoptic nucleus to induce sedation. GABAergic ventrolateral preoptic nucleus neurons of which Allo acts, innervate the ipsilateral tuberomammillary nucleus, a posterior hypothalamic cell group important in promoting arousal. The tuberomammillary nucleus, located on the ventrolateral edge of the posterior hypothalamus, contains neurons that co-express histamine and the inhibitory neurotransmitter GABA, and which project to the cerebral cortex, thalamus, and basal forebrain (Haas and Panula, 2003). These arousalpromoting, histaminergic tuberomammillary nucleus neurons are wake-active and are inhibited by the release of GABA and galanin by ventrolateral preoptic nucleus neurons. In short, the activated ventrolateral preoptic nucleus releases GABA to the $\mathrm{GABA}_{\mathrm{A}} \mathrm{R}$-containing sites of the tuberomammillary nucleus thus inhibiting release of arousal-promoting histamine into the cortex and forebrain to induce sedation. Through a wake-sleep neuronal network, at suprathreshold doses Allo allosterically potentiates GABA's apparent affinity for the $\mathrm{GABA}_{\mathrm{A}} \mathrm{R}$ to increase the chloride current of histaminergic neurons of the tuberomammillary nucleus causes sedation. The sedative response is not the primary regenerative target and sedation is less tolerable for treatment of chronic disease. A subsedative dose of Allo that retains activity at Allo-sensitive neural progenitor cells is optimal for regenerative responses and therapeutic development (Figure 3).

In a human clinical trial, a sedation-inducing dose of Allo briefly impaired episodic memory $10 \mathrm{~min}$ after the end of Allo intravenous infusion when peak blood levels were highest (Kask et al., 2008). Not surprisingly, a $\mathrm{GABA}_{\mathrm{A}} \mathrm{R}$ allosteric agonist induced temporary memory impairment in a way similar to benzodiazepines. Chronic treatment paradigms that mimic stress 
conditions have also been shown to inhibit memory (Turkmen et al., 2006). Allo administered twice daily at high doses to male rats for several consecutive days decreased performance on the Morris water maze, escape latency, path length and thigmotaxis (Turkmen et al., 2006).

Collectively, the data indicate that the sedative properties of Allo are dose dependent and duration of exposure dependent. Allo administered by multiple routes of administration exhibits an acceptable margin of safety.

\section{REGENERATIVE POTENTIAL OF THE HUMAN BRAIN MATTERS}

Most studies in AD mouse models, have reported decreased neurogenesis primarily in the hippocampal SGZ of the dentate gyrus and the SVZ lateral ventricles with association with cortical regions including the rostral migratory stream (Lazarov and Marr, 2010). There is strong evidence in AD animal models including the $3 \times \mathrm{TgAD}$ mouse that demonstrate reduced neurogenesis with degree of AD pathology (Wang et al., 2007, 2010; Rodriguez et al., 2008, 2009; Chen et al., 2011; Singh et al., 2012). Unexpectedly, in post-mortem brain sections from AD victims, doublecortin, a microtubule-associated protein expressed by neuronal precursors and immature neurons, was increased relative to control brain sections (Jin et al., 2004). Neural progenitors have been isolated in vitro from post-mortem 11-week post-natal and adult human brain demonstrating that neural progenitors are present throughout life (Palmer et al., 2001). Further studies are required to determine whether the doublecortin immunostaining findings were reproducible with other antibodies or preferably with BrdU or ${ }^{14} \mathrm{C}$ labels. It has been demonstrated that in humans without known neurological disorders, hippocampal neurogenesis occurs throughout adulthood and tapers modestly with advanced age (Spalding et al., 2013).

Humans exhibit substantial hippocampal neurogenesis within the SGZ (Spalding et al., 2013) and striatal neurogenesis associated with the SVZ lateral ventricles (Ernst et al., 2014). Humans, rather uniquely for mammals, do not demonstrate olfactory bulb neurogenesis, as the neuroblasts originating in the neurogenic niche of the lateral ventricle wall do not migrate to the olfactory bulb. Carbon-dated DNA within adult hippocampal neurons revealed that a substantial fraction of neurons were born during adulthood (Spalding et al., 2013; Ernst et al., 2014). Each year approximately $1.75 \%$ of the neurons turned over within the selfrenewing fraction with only a modest decline during aging. A best-fit scenario model predicted that approximately $35 \%$ of the hippocampal cells were cycling corresponding to slightly less than the proportion that constitute the entire dentate gyrus region. From these studies it was estimated that the hippocampal dentate gyrus of human brain produces around 700 new neurons per day. Enough neurons could be replaced in the hippocampus to theoretically regenerate the entire hippocampal neurogenic region over the lifespan suggesting the importance of neurogenesis. Compared to rodents, humans may rely on neurogenesis even more during the aging process (Spalding et al., 2013). In healthy aging, the decline of hippocampal neurogenesis is less than the rate of decline when adjusted for lifespan and compared with rodent models.
Following results demonstrating hippocampal neurogenesis throughout the lifespan, Frisen and colleagues utilized the same ${ }^{14} \mathrm{C}$ dating method to reveal abundant neuroblasts in the human striatum adjacent to the lateral ventricle wall and revealed a constant turnover/generation of striatal interneurons with and annual turnover rate of $2.7 \%$ within the renewing fraction (Ernst et al., 2014). This recent finding highlighted a major difference between human neurogenic niches vs. animal models. Rodents for example have well developed rostral migratory streams that send newborn SVZ neurons towards the olfactory bulb. Human brains were found to shunt the equivalent neurogenic niche cells to the striatum. In the brains of Huntington's disease patients, a disease related to the degeneration of striatal neurons (Zuccato et al., 2010; Walker et al., 2011), the patient cohort in the advanced state of the disease lacked these post-natally generated neurons (Ernst et al., 2014).

Once new neurons develop, the cells require approximately 2 months to mature both morphologically and physiologically, suggesting to us that an intermittent treatment regimen (Figure 3) would be required to stimulate regeneration in this neurological disorder. The timing of therapeutic intervention must accommodate the development period from which newborn cells acquire GABAergic and glutamatergic inputs and receptors. During this development period the young neurons are highly excitable with increased synaptic dynamics compared to mature neurons (Gage and Temple, 2013). This time course of regeneration, migration, differentiation, creates a temporal map that is coincident with Allo-induced proliferation, increased learning capacity and increased memory function (Brinton, 2013).

\section{GENDER MATTERS}

Neurological diseases that have varying prevalence, progression and severity between men and women include AD, Parkinson's disease, attention deficit/hyperactivity disorders, and schizophrenia (Gillies and Mcarthur, 2010). Sex differences have been noted in human safety studies of Allo, where the same intravenous dose in men and women resulted in maximum blood levels that were higher in men $150 \mathrm{nmol} / \mathrm{L}$ vs. $100 \mathrm{nmol} / \mathrm{L}$ in women, although volume of distribution, elimination half-life, and the area under the curve (AUC) adjusted for body weight did not differ (van Broekhoven et al., 2007).

Clinical differences between females and males may result from differences in brain morphology, neurochemistry, and functional outcomes. It is hypothesized that there is a critical hormone treatment window in the post-menopausal brain. The importance of regimen is again demonstrated when it was shown that continuous vs. cyclic progesterone administration resulted in disparate gene expression profiles in the brain (Zhao et al., 2012). Changes in neural gene expression profiles after alternative progesterone therapies highlights the importance of mimicking physiological profiles of neurosteroid exposure in order to maintain and improve neurological health and function (Zhao et al., 2012). Changes in pathophysiology due to gender may be important in evaluating both efficacy and side-effect profiles during therapeutic development (Figure 4). Early in 2014, a drug response gender difference prompted the FDA to issue a safety announcement and reduce by half the zolpidem (Ambien) dosage for women 

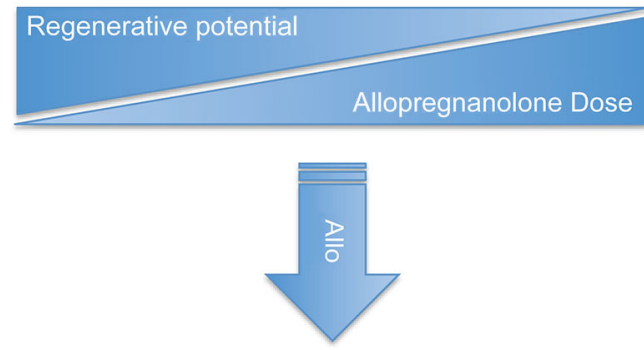

Moving Targets

Age

Hormone status

Metabolism

Physical health

Disease stage

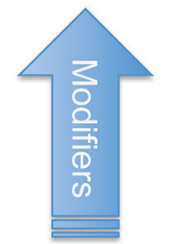

Static Variables

Gender

Genetics

FIGURE 4 | Design of clinical trials for allopregnanolone should consider both static variables and moving targets to treat neurological disorders. Gender and genetics are static variables that influence disease and response to treatment. Static variables impact the moving targets such as age, hormone status, metabolism, health, and disease progression. Successful clinical therapeutic strategies should be tailored for each disease state and should be monitored as the disease and treatment progresses. Dynamic biological processes require an understanding of disease system pathogenesis to select and modify the appropriate treatment regimen.

compared to men. ${ }^{1}$ As a result, zolpidem is now the only prescription drug with a different dose for men and women. Zolpidem, like Allo, is a $\mathrm{GABA}_{\mathrm{A}}$ agonist with sedative hypnotic actions in the wake-sleep neurocircuitry. Women metabolize and eliminate zolpidem slower than men, making them more susceptible to next morning impairment side effects.

Preclinically, a difference between sexes in Allo response was observed in our studies whereby male rats administered bolus injections of Allo had increased sensitivity to Allo's sedative effects, with greater time and levels of sedation compared to agematched female rats (Irwin et al., 2013). Allo may exert its effects on males and females differently, i.e., other than through binding postsynaptic $\mathrm{GABA}_{\mathrm{A}} \mathrm{Rs}$. The female brain may have a greater sensitivity to Allo's potentiation of GABA neurotransmission. In a global ischemia mouse model, females were neuroprotected at a dose of Allo four times lower than the required dose to protect males (Kelley et al., 2011). These data are surprising in light of evidence indicating that male brains have a greater number of $\mathrm{GABA}_{\mathrm{A}} \mathrm{R}$ binding sites relative to female brains (Juptner and Hiemke, 1990).

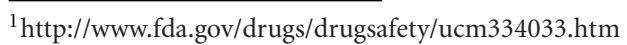

Cyclical changes of steroids during the estrous cycle can lead to changes in $\mathrm{GABA}_{\mathrm{A}} \mathrm{Rs}$ and during late diestrus new receptors have $\alpha_{4}, \beta_{1}$ and $\delta \mathrm{GABA}_{\mathrm{A}}$ receptor subunit expression (Lovick, $2008)$. As $\beta 1$ subunit containing receptors are extrasynaptic and carry tonic currents, upregulation should lead to a decrease in GABAergic inhibition (Lovick, 2008). Studies in male rats have shown that alterations in Allo plasma levels can, within minutes, modulate the amount of GABAergic inhibition in the periaqueductal gray matter. Function changes resulting from altered intrinsic excitability levels may affect therapeutic responsiveness (Lovick, 2008).

Overall, there is a recognized need for a better understanding of sex differences related to neurotherapeutic response and the clinical relevance of such differences to inform and improve drug development.

\section{DISEASE TARGET AND THERAPEUTIC GOALS MATTER ALZHEIMER'S DISEASE Disease target}

Regenerative system of the brain, cognition neural circuitry, and etiology of pathology.

\section{Therapeutic response to Allo}

Increased hippocampal neurogenesis, increase neural progenitor cell survival, and reverse learning and memory deficits, decreased microglial activation, and decreased amyloid-beta pathology (Brinton, 1994, 2013; Wang et al., 2010; Irwin et al., 2011; Singh et al., 2012; Lo et al., 2014).

\section{Targeted mechanism of action}

Potentiation of GABA at $\mathrm{GABA}_{\mathrm{A}} \mathrm{R}$ to depolarize neural stem cells; regulation of LXR and PXR in cholesterol homeostasis.

\section{Dose and treatment regimen}

Intermittent exposure in mice: $10 \mathrm{mg} / \mathrm{kg}$ once weekly for 6 months (Chen et al., 2011); $1 \mathrm{mg} / \mathrm{kg}$ SC single dose, $10 \mathrm{mg} / \mathrm{kg} \mathrm{SC}$ single dose, $20 \mathrm{mg} / \mathrm{kg}$ single dose (Wang et al., 2010); $10 \mathrm{mg} / \mathrm{kg}$ SC 3 times per week, for 3 months (Chen et al., 2011); $10 \mathrm{mg} / \mathrm{kg}$ once per month, single dose (Singh et al., 2012).

Allo and other trophic factors are decreased in blood and brain of $\mathrm{AD}$ patients compared to age-matched controls (Weill-Engerer et al., 2002; Marx et al., 2006; Naylor et al., 2010). Early AD is characterized by loss of episodic and semantic memory (Perry et al., 2000) and signifies hippocampal dysfunction. Diagnostic imaging studies using volumetric MRI revealed a decreased hippocampal volume due to neurodegeneration of gray matter in people diagnosed with amnestic mild cognitive impairment that will progress to $\mathrm{AD}$ (Whitwell et al., 2007). In AD, restoration of the dysfunctional neurogenic niche with intermittent pulses of Allo may regain neurological order while avoiding overstimulation.

We previously demonstrated a correlation between Alloinduced neural progenitor cell survival and improved memory function in the triple transgenic mouse model of AD (Brinton, 1994, 2013; Wang et al., 2010; Irwin et al., 2011; Singh et al., 2012). Consistent with the human AD brain neurosteroid profile (Weill-Engerer et al., 2002; Marx et al., 2006; Naylor et al., 
2010), basal concentration of Allo in blood plasma of wild-type mice of was significantly lower than in cortex indicating higher brain accumulation of Allo. Higher level of brain Allo could be attributed to locally synthesized Allo in specific brain regions required for synaptic function. We also found that $3 \times \mathrm{TgAD}$ mice had lower basal levels of Allo in the cerebral cortex $(3 \times \mathrm{TgAD}$, $6.49 \pm 2.02 \mathrm{ng} / \mathrm{g}$ vs. nonTg, $10.36 \pm 1.43 \mathrm{ng} / \mathrm{g}$ ), suggesting that there was either impairment of upstream Allo enzymatic production or accelerated Allo metabolism in 3xTgAD mice brain (Wang et al., 2010).

Within the SGZ and SVZ in male and female 3xTgAD mice a decline in neurogenesis is correlated with age-related AD-like pathology progression (Brinton and Wang, 2006; Rodriguez et al., 2008, 2009; Wang et al., 2010). Our studies have demonstrated that Allo promoted neurogenesis in the hippocampal SGZ to reverse learning and memory deficits (Wang et al., 2010). A study conducted in 3xTgAD mice subjected to an associative learning and memory task were analyzed and found increased neural progenitor cell survival of an intermittent treatment regimen with subcutaneous Allo $10 \mathrm{mg} / \mathrm{kg}$, 3 weeks after a single Allo treatment and post-behavioral analyses. After 3 weeks, Allo-treatment vs. vehicle control demonstrated that surviving BrdU-labeled cells were located deep within the granular cell layer, consistent with the migration pattern of newly formed cells from the SGZ to the granule cell layer (Wang et al., 2010). In an in vivo doseresponse study, $10 \mathrm{mg} / \mathrm{kg}$ SC Allo exerted the greatest neurogenic efficacy and was the dose chosen for chronic preclinical efficacy assessment (Wang et al., 2010).

To further assess the preclinical efficacy of Allo for AD, our group has conducted studies of long-term intermittent exposure to Allo. These studies with Allo were also initiated with 3-months of age mice, prior to overt intraneuronal $A \beta$. In addition to neurogenic efficacy, these long-term studies were allowed us to determine the disease modifying effects afforded by the therapeutic regimen. Our group tested three treatment regimens-once per month, once per week, and every other day (Chen et al., 2011). Overall, we found that the optimal treatment paradigm with subcutaneous Allo, administered once-per-week for 6-months was maximally efficacious for both neurogenic and anti-A $\beta$ endpoints (Importance of regimen discussed in greater detail above). Additionally, these studies demonstrated that together with the dosing frequency, the magnitude of pathology at the start of treatment intervention is critical to the window of therapeutic opportunity for Allo. Administration of Allo prior to and during the early stages of $\mathrm{AD}$ pathology significantly increased the regenerative response in brain while additionally reducing burden of pathology in an AD mouse model (Chen et al., 2011). In contrast, Allo treatment initiated at the point of $\mathrm{A} \beta$ plaque generation was not efficacious indicating that Allo targets regenerative and pathology reducing mechanisms present during the early to mid stages of the disease (Chen et al., 2011). After intraneuronal A $\beta$ is extracellularly distributed, Allo's efficacy becomes markedly diminished. Based on a collective body of preclinical data evaluating dose and route (Irwin et al., 2011; Brinton, 2013; Irwin and Brinton, 2014), we have selected the once per week regimen to move forward to FDA-compliant chronic toxicology studies and early phase clinical trials.

\section{PARKINSON'S DISEASE \\ Disease target}

Regenerate dopaminergic system of the brain and etiology of pathology.

\section{Therapeutic response to Allo}

Neurogenesis in the substantia nigra, functional improvement in motor control (Adeosun et al., 2012), modulates dopamine release (Rouge-Pont et al., 2002).

\section{Dose and treatment regimen}

Intermittent exposure: $10 \mathrm{mg} / \mathrm{kg}$ once a week for 2 weeks in mice (Adeosun et al., 2012).

Clinical studies investigating the levels of endogenous Allo in PD patients demonstrated that in males, the levels of endogenous Allo were decreased both peripherally and in the CNS (di Michele et al., 2003, 2013). While Allo concentrations in specific human brain regions affected by PD has not been studied, in healthy women, the highest Allo levels were observed in the substantia nigra (SN) and basal hypothalamus (Bixo et al., 1997). The therapeutic goals for exogenous Allo are the modulation of dopamine release, restoration of neuroprotection, modulation of basal GABAergic tone, and neuroregeneration (Luchetti et al., 2010, 2011; Adeosun et al., 2012; di Michele et al., 2013). As in $\mathrm{AD}$, the dose and therapeutic regimen must be carefully considered, as low doses Allo increases dopamine release, but at high doses decreases release (Rouge-Pont et al., 2002). In preclinical in vivo studies, once weekly Allo administration has demonstrated functional improvement (Adeosun et al., 2012).

\section{MULTIPLE SCLEROSIS}

\section{Disease target}

White matter regeneration in the peripheral and central nervous systems, reduce inflammation, etiological mechanism of disease, and prevention of relapse.

\section{Therapeutic response to Allo}

Oligogenesis (Garay et al., 2012; Schumacher et al., 2014), neurogenesis (Ghoumari et al., 2003; Gago et al., 2004), cytoprotective, promyelination (Melcangi et al., 1999; Noorbakhsh et al., 2011), anti-inflammatory (Noorbakhsh et al., 2011), reduced disease severity (Noorbakhsh et al., 2011), innate immune function modulator (Noorbakhsh et al., 2014).

\section{Dose and treatment regimen}

Continuous exposure: daily IP $10 \mathrm{mg} / \mathrm{kg}$ for 28 days in mice (Melcangi et al., 1999). Intermittent paradigm: $1 \mathrm{mg}$ SC every 4 days for 1 month in rats (Noorbakhsh et al., 2011).

The peripheral nervous system synthesizes steroid hormones, including progesterone, and possesses the enzymes required to convert these molecules to neuroactive metabolites, including Allo (Melcangi et al., 1999). In cases where the endogenous levels are insufficient, treatment with exogenous Allo could produce therapeutic benefit (Melcangi et al., 1999). Analyses of endogenous Allo showed that in MS patients, the Allo concentration in white matter was significantly decreased, demonstrating the potential for Allo as a potential therapeutic for this as yet unmet, 
clinical need (Noorbakhsh et al., 2011). A number of preclinical in vivo and in vitro studies have demonstrated the potential for Allo as a MS therapeutic through its anti-inflammatory effects, neurogenesis, and induction of myelin production (Melcangi et al., 1999; Ghoumari et al., 2003; Gago et al., 2004; Noorbakhsh et al., 2011). Common themes, seen in Allo studies for the disease states presented above, also apply to its utilization for MS. Efficacy is limited in late-stage disease, indicating that the system must retain neurogenic potential for therapeutic effect (Melcangi et al., 1999). Allo dosage and treatment regimen have been shown to be critical factors in study design. Positive effects of treatment were limited in in vitro studies when length of treatment was less than $24 \mathrm{~h}$ (Melcangi et al., 1999). As in AD, more Allo is not beneficial, and in vitro dose-response curve studies have demonstrated that the positive proliferative effects of Allo peak at $10 \mathrm{nM}$ doses, and decrease with increasing doses (Gago et al., 2004).

\section{NIEMANN-PICK TYPE C \\ Disease target}

Cholesterol trafficking and clearance system of the brain and etiology of disease.

\section{Therapeutic response to Allo}

Increased survival, decreased rate of motor control decline, increased neuronal survival, decreased cholesterol accumulation (Griffin et al., 2004), and reduced oxidative stress (Zampieri et al., 2009).

\section{Dose and treatment regimen}

Single dose exposure: $25 \mathrm{mg} / \mathrm{kg} \mathrm{SC}$, single injection in mice (Griffin et al., 2004). Continuous exposure: 0.5-2 mg in drinking water (ascending dose; lifetime treatment); $250 \mathrm{mg} / 90$ days SC implant (lifetime treatment) in mice (Griffin et al., 2004).

NPC is a fatal, neurodegenerative, lysosomal storage disorder that affects cholesterol metabolism due to autosomal recessive mutations in the NPC1 and LPC2 loci. Allo has been studied for its therapeutic effect on NPC, which is characterized by defective trafficking of intracellular cholesterol and lysosomal accumulation of unesterified cholesterol gangliosides and other lipids leading to neurological deterioration and degenerating motor and cognitive function. Characterization of the NPC mouse model suggested dysfunctional steroidogenesis from cholesterol, giving credence to the indication for Allo (Griffin et al., 2004). In vivo studies have demonstrated that Allo, administered using continuous exposure paradigms results in improved outcomes, including survival and a decreased rate of decline of locomotion and motor coordination (Griffin et al., 2004). In addition to these functional improvements, histological examination demonstrated increased cerebellar neuron survival and decreased accumulation of cortical gangliosides (Griffin et al., 2004). Interestingly, in this disease state, continuous Allo administration via treated water resulted in superior survival outcomes vs. a single Allo SC dose. As has been shown in other disease states treated with Allo, timing of the single-dose injection is vital. Outcomes are best when Allo is administered early postnatally as efficacy diminishes and is quickly lost with advancing disease state (Griffin et al., 2004). In vitro studies have demonstrated a significant antioxidant function of Allo, but this remains to be translated to in vivo preclinical models (Zampieri et al., 2009).

\section{FXTAS AND FRAGILE X SYNDROME Disease target}

Regenerative system of the brain and etiology of disease.

\section{Therapeutic response to Allo}

Improved functional electrical impairments in vitro culture of neurons from a mouse model of the disease (Cao et al., 2012).

\section{Dose and treatment regimen}

0.01-1 $\mu \mathrm{M}$ (in vitro) (Cao et al., 2012).

Preclinical studies demonstrate that Allo is efficacious in neural cells isolated from a fragile X-associated tremor/ataxia syndrome (FXTAS) mouse model (Cao et al., 2012). This mouse model has defects in neuronal morphology and migration. FXTAS related defects occur in basal electrical activity exhibited by permutation CGG repeat expansion-carrying neurons associated with a gain-of-function in type-I mGluRs and/or a loss-offunction in $\mathrm{GABA}_{\mathrm{A}} \mathrm{R}$ signaling. Allo acutely improved the functional impairments as measured by electrical burst firing, in this preclinical model.

Furthermore, an Allo analog, ganaxolone, formulated in an oral suspension, given in three divided doses (ClinicalTrials.gov identifier: NCT01725152) is currently in Phase 2 proof-ofconcept study in children with fragile $\mathrm{X}$ syndrome. Fragile $\mathrm{X}$ syndrome is the most common inherited form of cognitive impairment results from a single-gene disorder associated with autism. The aim of the study is to assess the safety, tolerability and efficacy of ganaxolone for treatment of anxiety and attention deficits in subjects with fragile $\mathrm{X}$ syndrome. The clinical trial is designed to test ganaxolone treatment compared to placebo on measures of anxiety and attention via several neuropsychological and psychometric tests.

\section{DIABETIC NEUROPATHY Disease target}

Regenerate peripheral nerve, reduce pain, increase conductivity of peripheral nerves, and etiological mechanism of disease.

\section{Therapeutic response to Allo}

Decreased expression of apoptosis mediators, increased nociception threshold (Afrazi et al., 2014), increased nerve conduction velocity, and restored intra-epidermal nerve fiber density (Leonelli et al., 2007).

\section{Dose and treatment regimen}

Intermittent exposure in rats: $5 \mathrm{mg}$ or $20 \mathrm{mg} / \mathrm{kg}$, gastric lavage, for 8 weeks (Afrazi et al., 2014); $3.3 \mathrm{mg} / \mathrm{kg}$ SC every 4 days for 8 doses; $3.3 \mathrm{mg} / \mathrm{kg}$ SC every 2 days for 16 doses (Leonelli et al., 2007).

Diabetic neuropathy is a unifying term for a heterogenous assembly of symptoms resulting from long-term glucose instability. Neuronal damage, dysfunction and apoptosis can present in patients in a myriad of ways including spontaneous pain, hypoesthesia, allodynia and hyperalegsia. Neurosteroid levels have been 
shown to fall in neuropathic pain conditions (Patte-Mensah et al., 2005; Saredi et al., 2005), validating the assessment of Allo for this indication. In vivo studies have demonstrated the effect of Allo on improving nociceptive threshold and decreased expression of apoptosis mediators (Afrazi et al., 2014). The theme of an optimal dosage regimen is continued here; Allo demonstrated superior restoration of nerve conduction velocity and intra-epidermal nerve fiber density when administered every other day for 30 days vs. every 4 days for 28 days (Leonelli et al., 2007). As in $\mathrm{AD}$ and $\mathrm{MS}$, a higher Allo dose is not beneficial, and an in vitro dose-response curve study have demonstrated that the positive cell viability effects of Allo in glucose induced cell toxicity peak at the $2.5 \mu \mathrm{M}$ dose, and decrease with increasing doses (Afrazi et al., 2014).

\section{STATUS EPILEPTICUS}

\section{Disease target}

Spontaneous seizure activity of the brain.

\section{Therapeutic response to Allo}

Dampens epileptic seizure activity and reduce neuroexcitotoxicity (Rogawski et al., 2013).

\section{Dose and treatment regimen}

Immediate and continuous treatment regimen in $6 \mathrm{~Hz}$ seizure model, $1.5 \mathrm{mg} / \mathrm{kg}$ Allo IV conferred seizure protection within 1 min after dosing in mice (Rogawski et al., 2013; Zolkowska et al., 2013).

Most seizures are spontaneously terminated within a short period of time because of endogenous inhibitory mechanisms including actions of Allo on $\mathrm{GABA}_{\mathrm{A}}$ Rs. However, when seizures do not stop spontaneously, this results in status epilepticus, a life-threatening neurological emergency condition. Allo is currently in clinical trials on emergency basis for certain cases of status epilepticus (Rogawski et al., 2013). Previously, ganaxolone was being developed for infantile spasms (Gasior et al., 2000; Kerrigan et al., 2000; Kaminski et al., 2004). Standard treatment for status epilepticus is administration of benzodiazepines but in many cases these quickly become ineffective. $\mathrm{GABA}_{\mathrm{A}} \mathrm{Rs}$ are in a continuous cycle of insertion into the cell membrane and internalization (Goodkin et al., 2005). Internalization of $\mathrm{GABA}_{\mathrm{A}}$ Rs occurs through clathrin-dependent endocytosis. This process is activated by calcium-phospholipid dependent protein kinase C (Chapell et al., 1998; Filippova et al., 2000) and brain-derived neurotrophic factor (Jovanovic et al., 2004). Internalization of the surface $\mathrm{GABA}_{\mathrm{A}}$ Rs correlates with a reduced response to GABA, whereas inhibition of internalization results in increased amplitude of synaptic $\mathrm{GABA}_{\mathrm{A}} \mathrm{R}$ currents (Kittler et al., 2000).

The benzodiazepine-binding site within the $\mathrm{GABA}_{\mathrm{A}} \mathrm{R}$ complex is located within the $\alpha$-subunit interface with the $\delta$-subunit and after synaptic receptor internalization, epilepsy patients often become resistant to therapy. Neurosteroid binding sites are within the $\alpha$-subunit or $\alpha / \beta$ interface and are not reliant on the $\delta$-subunit composition. Extrasynaptic $\mathrm{GABA}_{\mathrm{A}}$ Rs that contain a $\delta$-subunit rather than a $\gamma$-subunit are sensitive Allo molecular targets that do not have drug resistance complications and improve treatment of seizures. Recent resurgence of interest in Allo and its analogs has prompted attention for this important disease application to dampen epileptic seizure activity and reduce neuroexcitotoxicity (Rogawski et al., 2013).

\section{TRAUMATIC BRAIN INJURY Disease target}

Glutamate excitotoxicity systems of the brain.

\section{Therapeutic response to Allo}

Anti-inflammatory (VanLandingham et al., 2007), neuroprotective (Sayeed et al., 2009), anti-convulsant (Rogawski et al., 2013).

\section{Dose and treatment regimen}

Immediate and continuous exposure. Within $8 \mathrm{~h}$ after injury, a continuous IV Allo regimen for traumatic brain injury (TBI) is administered during a 4-day treatment period followed by a 1-day dose de-escalation period in humans (ClinicalTrials.gov identifier: NCT01673828) (Rogawski et al., 2013).

The adult brain has been shown to possess regenerative mechanisms after infarct and injury. In rodents, proliferation in the SVZ, migration of new neurons to peri-infarct site, and survival of these new neurons has been demonstrated following stroke and involves the inflammatory cytokines and chemokines systems to aid recovery (He et al., 2004b; Djebaili et al., 2005). It has been hypothesized that angiogenesis leads to functional recovery through its interaction with one or more aspects of tissue repair, including neurogenesis (Carmichael, 2010). There is currently no effective treatment available for TBI victims. TBI may induce coma or a minimally conscious state and may lead to neurobehavioral deficits including cognitive deficits. Long-term consequences of TBI include increased risk for epileptic seizures, PD, and AD (Annegers et al., 1998; Mueller et al., 2009; Hutson et al., 2011; Johnson et al., 2012). A challenge for TBI research is the extent of heterogeneity of these brain injuries and the delayed secondary injuries due to increases in intracranial pressure, hypoxia, and glutamate excitotoxicity (Mueller et al., 2009). A TBI case study of two patients who recovered after years in a state of minimal consciousness suggests that brain regeneration and specific axonal regrowth to improve quality of life is possible even after severe TBI (Voss et al., 2006).

Allo is currently in clinical trials to assess the safety and efficacy of Allo in improving neurobehavioral outcome and reducing mortality in adults with moderate and severe TBI (ClinicalTrials.gov identifier: NCT01673828). Within 8 h after injury, a continuous IV Allo regimen for TBI is administered during a 4-day treatment period followed by a 1-day dose de-escalation period (ClinicalTrials.gov identifier: NCT01673828). This continuous treatment regimen is very different from the regenerative regimen approach taken for Allo in chronic neurodegenerative diseases. This regimen takes advantage of the anticonvulsant mechanisms of Allo action to limit acute brain excitoxicity (Figure 3). Allo and its precursor progesterone acutely reduce inflammatory cytokines after brain injury (He et al., 2004a,b; Djebaili et al., 2005). Allo has been shown to upregulate CD55, a cell surface protein that inhibits convertase enzymes to reduce neuroinflammation (VanLandingham et al., 2007). Another possible mechanism of 
Allo-induced neuroprotection is a direct inhibition of the mitochondrial permeability transition pore. By this mechanism, Allo was shown to inhibit calcium ion-triggered swelling in functionally intact rat liver and brain mitochondria (Sayeed et al., 2009).

\section{INTEGRATION OF TRANSLATIONAL DETERMINANTS INTO THE CLINICAL TRIAL DESIGN FOR AD AND OTHER DISORDERS MATTERS}

Fundamental translational determinants of success are welldefined mechanisms of action, dose-response relationships, and optimal therapeutic regimen. Mechanistically, a key to therapeutic success is an understanding of the intended activated pathways as well as those that are unintentionally activated. This is not always possible but always beneficial. A well-defined understanding of dose-response relationship includes doses that are sub-optimal and which induce toxicity or off-target effects. In the case of Allo, the dose-response relationship indicates that a sedative dose suppresses regeneration and thus establishes the maximally tolerated dose. Further, daily exposure to Allo at a non-sedative dose also suppresses regeneration. The dose and exposure relationships provide critical information for clinical trial design as well as providing key insights into the regenerative system of the brain.

The maximally tolerated dose will depend on the neurological condition, intended mechanism of action, and the therapeutic goals (Figure 3). For example, a low dose of Allo with intermittent exposure is optimal for activating regenerative responses. Whereas, TBI and status epilepticus require emergency suppression of glutamate excitotoxicity necessitating a high dose of Allo administered by continuous infusion.

Clinical trial design is inextricably linked to therapeutic success. Recently, the Food and Drug Administration (FDA) released a draft guidance document for developing drugs for early-stage AD trials (Food Drug Administration, Center for Drugs Evaluation Research, 2013) that aimed to improve the design of future AD clinical studies. The FDA guidance emphasized the use of the Clinical Dementia Rating Scale as a primary clinical scale to accelerate development of $\mathrm{AD}$ drugs. In addition to these cognitive and functional measures, exploratory outcomes for early stage $\mathrm{AD}$ trials can be incorporated into the design as secondary outcomes (Schneider, 2014). Exploratory outcomes are useful to detect responsiveness to new therapies such as correlations between neuroregenerative indicators and improvement in brain activity (Mullard, 2012, 2013; Schneider, 2014).

Adaptive clinical trials are designed to conduct interim analyses that are prospectively planned (Food Drug Administration, Center for Drugs Evaluation Research, 2010). An adaptive design affords the opportunity to modify one or more aspects of the study based on a hypothesis-driven analysis of the data. The benefit of an adaptive design is the opportunity to learn about the impact of the therapeutic agent early in the course of the study and to make course corrections earlier rather than later. These analyses would be hypothesis driven and based on predictive biomarkers of efficacy.

What defines biomarkers that align with stage of disease and are predictive of therapeutic efficacy? Potential biomarkers of efficacy relevant to regeneration could be evident as either decreased rate of degeneration or an increased rate of structural recovery. Thus we reasoned that if Allo was promoting regeneration in the brain, that regeneration could be evident in MRI-based measures of hippocampal volume, diffusion tensor imaging of white matter, and resting default mode network (Brinton, 2013). If structural integrity is related to function, then one would predict a delay in severity of dementia and or recovery of cognitive function. We anticipate, based on the temporal requirements for regeneration in the context of a degenerated brain, that the regeneration of the neural circuitry that underlies the resting default mode network has the greatest probability of being the first imaging biomarker to exhibit change over time.

Clinical trials of potential disease modifying agents require the ability to characterize a well-defined study cohort (Sperling et al., 2011a). The National Institutes of Aging and the Alzheimer's Association published disease-staging criteria that describe the clinical stages of AD (Albert et al., 2011). For clinical development of Allo, initial targeted populations are those with mild cognitive impairment or early AD (Brinton, 2013). These populations were targeted based on preclinical analyses indicating that Allo exerted a regenerative response in transgenic $\mathrm{AD}$ mice with burden of pathology relevant to early stage $\mathrm{AD}$. These animals exhibited cognitive and neurogenic deficits that were reversed by Allo (Brinton, 2013). At later stages of the disease, the regenerative capacity was depleted and thus not appropriate for a therapeutic that promotes endogenous regeneration (Brinton, 2013).

Collectively, it is clear that clinical trial testing of Allo across multiple neurodegenerative diseases will require translational research specific to the disease, dosing to the intended target, treatment regimen specific to the respective system, and study population specific to stage of disease.

\section{CONCLUDING REMARKS}

The goal of this review was to integrate existing knowledge relevant to translational development of Allo as a therapeutic agent for multiple neurological disorders. There are multiple leverage points across programs of therapeutic development that could significantly accelerate time-to-clinical trial of Allo in each of these conditions (Figure 5). Allo activates multiple systems in multiple cell types in multiple anatomical regions with therapeutic implications for multiple diseases. Each neurological disease has specific Allo dose and therapeutic regimen requirements that must be tested preclinically and must be carefully translated to clinical study design. Leverage points—such as preclinical efficacy data, preclinical toxicology data, regulatory knowledge, access to clinical-grade material, and access to clinical data matter to development of expedited timelines to utilize Allo across these disorders (Figure 5). For Allo to reach its potential as a therapeutic option, the formulation, dosing regimen, and route of administration are critical determinants of success. Considerations of gender, genetics, age, and progression of disease for both preclinical translational analyses and clinical trials are critical (Figure 4).

The therapeutic potential of Allo for multiple neurological diseases is increasingly appreciated. Different etiologies, different courses of disease progression, different mechanisms involved in the disease, will impact the therapeutic efficacy of Allo. In 


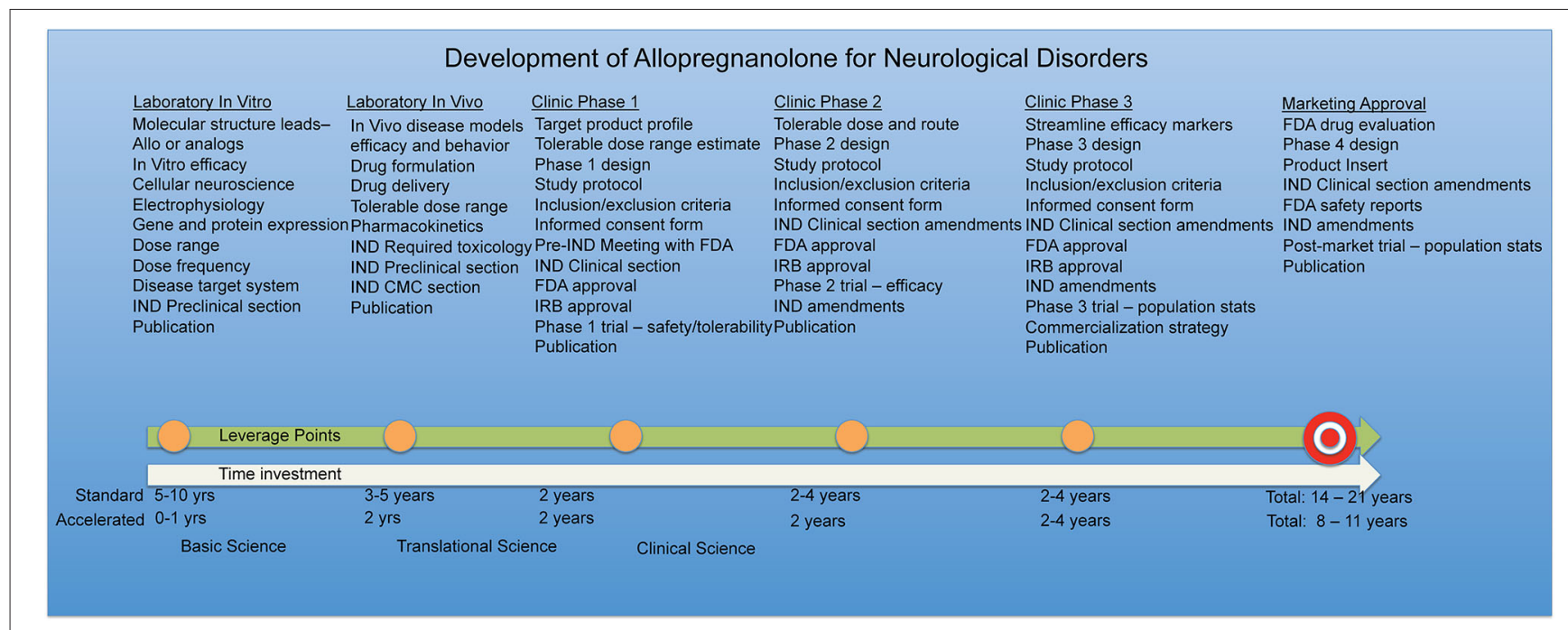

FIGURE 5 | Development of allopregnanolone for neurological disorders. Leverage points along the standard timeline of 12 years and up to $20+$ years as drug development proceeds to the marketing approval target. By sharing resources and information, it is plausible to accelerate therapeutic development timelines to 8 years or less, completing clinical trials more rapidly for unmet medical needs. turn, it is essential that translational research target each of the neurological disorders and take into consideration the similarities and differences in molecular targets and etiology of disease. To suppress neuronal excitability in TBI or epilepsy, it makes sense to inhibit excitability as early as possible following injury. In other cases, maximizing GABAergic suppression of the brain in the absence of glutamate excitotoxicity is unlikely to have therapeutic benefit and could induce harm. Pragmatically, this translates into dosage levels and treatment regimens tailored to the neurological disorder and therapeutic goals in the context of the relevant systems biology.

We have reviewed herein compelling preclinical discovery outcomes that strongly suggest the therapeutic potential of Allo. Translation of Allo to clinical studies requires systematic establishment of the optimal target engagement, dose, treatment regimen, duration of treatment, and safety. What remains is to leverage the discovery science into the path of translation. Fortunately, and remarkably, there are multiple opportunities to leverage existing translational knowledge and to systematically apply that knowledge in disease relevant models to accelerate determination of Allo efficacy across multiple disease states.

\section{ACKNOWLEDGMENTS}

This research was supported by grants from National Institute on Aging U01 AG031115, U01 AG047222, UF1 AG046148, Alzheimer's Drug Discovery Foundation, and the Kenneth T. and Eileen L. Norris Foundation to Roberta Diaz Brinton.

\section{REFERENCES}

Abramian, A. M., Comenencia-Ortiz, E., Modgil, A., Vien, T. N., Nakamura, Y., Moore, Y. E., et al. (2014). Neurosteroids promote phosphorylation and membrane insertion of extrasynaptic GABAA receptors. Proc. Natl. Acad. Sci. U S A 111, 7132-7137. doi: 10.1073/pnas.1403285111

Adeosun, S. O., Hou, X., Jiao, Y., Zheng, B., Henry, S., Hill, R., et al. (2012). Allopregnanolone reinstates tyrosine hydroxylase immunoreactive neurons and motor performance in an MPTP-lesioned mouse model of Parkinson's disease. PLoS One 7:e50040. doi: 10.1371/journal.pone.0050040

Afrazi, S., Esmaeili-Mahani, S., Sheibani, V., and Abbasnejad, M. (2014). Neurosteroid allopregnanolone attenuates high glucose-induced apoptosis and prevents experimental diabetic neuropathic pain: in vitro and in vivo studies. J. Steroid Biochem. Mol. Biol. 139, 98-103. doi: 10.1016/j.jsbmb.2013. 10.010

Albert, M. S., Dekosky, S. T., Dickson, D., Dubois, B., Feldman, H. H., Fox, N. C., et al. (2011). The diagnosis of mild cognitive impairment due to Alzheimer's disease: recommendations from the National Institute on agingAlzheimer's association workgroups on diagnostic guidelines for Alzheimer's disease. Alzheimers Dement. 7, 270-279. doi: 10.1016/j.jalz.2011.03.008

Annegers, J. F., Hauser, W. A., Coan, S. P., and Rocca, W. A. (1998). A populationbased study of seizures after traumatic brain injuries. N. Engl. J. Med. 338, 20-24. doi: 10.1056/nejm199801013380104

Becker, R. E., Greig, N. H., Giacobini, E., Schneider, L. S., and Ferrucci, L. (2014). A new roadmap for drug development for Alzheimer's disease. Nat. Rev. Drug Discov. 13:156. doi: 10.1038/nrd3842-c2

Belelli, D., and Lambert, J. J. (2005). Neurosteroids: endogenous regulators of the GABA(A) receptor. Nat. Rev. Neurosci. 6, 565-575. doi: 10.1038/nrn1703

Benarroch, E. E. (2007). Neurosteroids: endogenous modulators of neuronal excitability and plasticity. Neurology 68, 945-947. doi: 10.1212/01.wnl. 0000257836.09570.e1

Bengtsson, S. K., Johansson, M., Backstrom, T., and Wang, M. (2012). Chronic allopregnanolone treatment accelerates Alzheimer's disease development in AbetaPP(Swe)PSEN1(DeltaE9) mice. J. Alzheimers Dis. 31, 71-84. doi: 10. 3233/JAD-2012-120268

Bengtsson, S. K., Johansson, M., Backstrom, T., Nitsch, R. M., and Wang, M. (2013). Brief but chronic increase in allopregnanolone cause accelerated AD pathology differently in two mouse models. Curr. Alzheimer Res. 10, 38-47. doi: 10.2174/1567205011310010006

Bernardi, F., Lanzone, A., Cento, R. M., Spada, R. S., Pezzani, I., Genazzani, A. D., et al. (2000). Allopregnanolone and dehydroepiandrosterone response to corticotropin-releasing factor in patients suffering from Alzheimer's disease and vascular dementia. Eur. J. Endocrinol. 142, 466-471. doi: 10.1530/eje.0. 1420466

Bixo, M., Andersson, A., Winblad, B., Purdy, R. H., and Backstrom, T. (1997). Progesterone, 5alpha-pregnane-3,20-dione and 3alpha-hydroxy-5alphapregnane-20-one in specific regions of the human female brain in different endocrine states. Brain Res. 764, 173-178. doi: 10.1016/s0006-8993(97) 00455-1 
Brinton, R. D. (1994). The neurosteroid 3 alpha-hydroxy-5 alpha-pregnan-20-one induces cytoarchitectural regression in cultured fetal hippocampal neurons. J. Neurosci. 14, 2763-2774.

Brinton, R. D. (2013). Neurosteroids as regenerative agents in the brain: therapeutic implications. Nat. Rev. Endocrinol. 9, 241-250. doi: 10.1038/nrendo. 2013.31

Brinton, R. D., and Wang, J. M. (2006). Preclinical analyses of the therapeutic potential of allopregnanolone to promote neurogenesis in vitro and in vivo in transgenic mouse model of Alzheimer's disease. Curr. Alzheimer Res. 3, 11-17. doi: 10.2174/156720506775697160

Cao, Z., Hulsizer, S., Tassone, F., Tang, H. T., Hagerman, R. J., Rogawski, M. A., et al. (2012). Clustered burst firing in FMR1 premutation hippocampal neurons: amelioration with allopregnanolone. Hum. Mol. Genet. 21, 2923-2935. doi: 10. 1093/hmg/dds118

Carmichael, S. T. (2010). Translating the frontiers of brain repair to treatments: starting not to break the rules. Neurobiol. Dis. 37, 237-242. doi: 10.1016/j.nbd. 2009.09.005

Chapell, R., Bueno, O. F., Alvarez-Hernandez, X., Robinson, L. C., and Leidenheimer, N. J. (1998). Activation of protein kinase C induces gammaaminobutyric acid type A receptor internalization in Xenopus oocytes. J. Biol. Chem. 273, 32595-32601. doi: 10.1074/jbc.273.49.32595

Chen, S., Wang, J. M., Irwin, R. W., Yao, J., Liu, L., and Brinton, R. D. (2011). Allopregnanolone promotes regeneration and reduces beta-amyloid burden in a preclinical model of alzheimer's disease. PLoS One 6:e24293. doi: 10. 1371/journal.pone.0024293

Crowley, S. K., and Girdler, S. S. (2014). Neurosteroid, GABAergic and hypothalamic pituitary adrenal (HPA) axis regulation: what is the current state of knowledge in humans? Psychopharmacology (Berl) doi: 10.1007/s00213-0143572-8. [Epub ahead of print].

Damianisch, K., Rupprecht, R., and Lancel, M. (2001). The influence of subchronic administration of the neurosteroid allopregnanolone on sleep in the rat. Neuropsychopharmacology 25, 576-584. doi: 10.1016/s0893-133x(01) 00242-1

Demattos, R. B., Lu, J., Tang, Y., Racke, M. M., Delong, C. A., Tzaferis, J. A., et al. (2012). A plaque-specific antibody clears existing beta-amyloid plaques in Alzheimer's disease mice. Neuron 76, 908-920. doi: 10.1016/j.neuron.2012. 10.029

di Michele, F., Longone, P., Romeo, E., Lucchetti, S., Brusa, L., Pierantozzi, M., et al. (2003). Decreased plasma and cerebrospinal fluid content of neuroactive steroids in Parkinson's disease. Neurol. Sci. 24, 172-173. doi: 10.1007/s10072003-0115-1

di Michele, F., Luchetti, S., Bernardi, G., Romeo, E., and Longone, P. (2013). Neurosteroid and neurotransmitter alterations in Parkinson's disease. Front. Neuroendocrinol. 34, 132-142. doi: 10.1016/j.yfrne.2013.03.001

Dieriks, B. V., Waldvogel, H. J., Monzo, H. J., Faull, R. L., and Curtis, M. A. (2013). $\mathrm{GABA}(\mathrm{A})$ receptor characterization and subunit localization in the human sub ventricular zone. J. Chem. Neuroanat. 52, 58-68. doi: 10.1016/j.jchemneu.2013. 06.001

Djebaili, M., Guo, Q., Pettus, E. H., Hoffman, S. W., and Stein, D. G. (2005). The neurosteroids progesterone and allopregnanolone reduce cell death, gliosis and functional deficits after traumatic brain injury in rats. J. Neurotrauma 22, 106 118. doi: 10.1089/neu.2005.22.106

Dong, E., Matsumoto, K., Uzunova, V., Sugaya, I., Takahata, H., Nomura, H., et al. (2001). Brain 5alpha-dihydroprogesterone and allopregnanolone synthesis in a mouse model of protracted social isolation. Proc. Natl. Acad. Sci. U S A 98, 28492854. doi: 10.1073/pnas.051628598

Donkin, J. J., Stukas, S., Hirsch-Reinshagen, V., Namjoshi, D., Wilkinson, A., May, S., et al. (2010). ATP-binding cassette transporter Al mediates the beneficial effects of the liver-X-receptor agonist GW3965 on object recognition memory and amyloid burden in APP/PS1 mice. J. Biol. Chem. 285, 34144-34154. doi: 10. 1074/jbc.m110.108100

Ernst, A., Alkass, K., Bernard, S., Salehpour, M., Perl, S., Tisdale, J., et al. (2014). Neurogenesis in the striatum of the adult human brain. Cell 156, 1072-1083. doi: 10.1016/j.cell.2014.01.044

Fan, X., Kim, H. J., Bouton, D., Warner, M., and Gustafsson, J. A. (2008). Expression of liver X receptor beta is essential for formation of superficial cortical layers and migration of later-born neurons. Proc. Natl. Acad. Sci. U S A 105, 13445-13450. doi: 10.1073/pnas.0806974105
Filippova, N., Sedelnikova, A., Zong, Y., Fortinberry, H., and Weiss, D. S. (2000). Regulation of recombinant gamma-aminobutyric acid (GABA)(A) and GABA(C) receptors by protein kinase C. Mol. Pharmacol. 57, 847-856.

Food Drug Administration, Center for Drugs Evaluation Research. (2010). Guidance for Industry: Adaptive Design Clinical Trials for Drugs and Biologics. Maryland: FDA.

Food Drug Administration, Center for Drugs Evaluation Research. (2013). Guidance for Industry: Alzheimer's Disease: Developing Drugs for the Treatment of Early Stage Disease. Maryland: FDA.

Gage, F. H., and Temple, S. (2013). Neural stem cells: generating and regenerating the brain. Neuron 80, 588-601. doi: 10.1016/j.neuron.2013.10.037

Gago, N., El-Etr, M., Sananes, N., Cadepond, F., Samuel, D., Avellana-Adalid, V., et al. (2004). 3alpha,5alpha-Tetrahydroprogesterone (allopregnanolone) and gamma-aminobutyric acid: autocrine/paracrine interactions in the control of neonatal PSA-NCAM+ progenitor proliferation. J. Neurosci. Res. 78, 770-783. doi: 10.1002/jnr.20348

Garay, L. I., Gonzalez Deniselle, M. C., Brocca, M. E., Lima, A., Roig, P., and De Nicola, A. F. (2012). Progesterone down-regulates spinal cord inflammatory mediators and increases myelination in experimental autoimmune encephalomyelitis. Neuroscience 226, 40-50. doi: 10.1016/j.neuroscience.2012. 09.032

Gasior, M., Ungard, J. T., Beekman, M., Carter, R. B., and Witkin, J. M. (2000). Acute and chronic effects of the synthetic neuroactive steroid, ganaxolone, against the convulsive and lethal effects of pentylenetetrazol in seizure-kindled mice: comparison with diazepam and valproate. Neuropharmacology 39, 1184 1196. doi: 10.1016/s0028-3908(99)00190-2

Gee, K. W., Bolger, M. B., Brinton, R. E., Coirini, H., and Mcewen, B. S. (1988). Steroid modulation of the chloride ionophore in rat brain: structure-activity requirements, regional dependence and mechanism of action. J. Pharmacol. Exp. Ther. 246, 803-812.

Gee, K. W., Chang, W. C., Brinton, R. E., and Mcewen, B. S. (1987). GABAdependent modulation of the $\mathrm{Cl}$ - ionophore by steroids in rat brain. Eur. J. Pharmacol. 136, 419-423. doi: 10.1016/0014-2999(87)90317-7

Genazzani, A. R., Bernardi, F., Stomati, M., Monteleone, P., Luisi, S., Rubino, S., et al. (2000). Effects of estradiol and raloxifene analog on brain, adrenal and serum allopregnanolone content in fertile and ovariectomized female rats. Neuroendocrinology 72, 162-170. doi: 10.1159/000054583

Genazzani, A. R., Petraglia, F., Bernardi, F., Casarosa, E., Salvestroni, C., Tonetti, A., et al. (1998). Circulating levels of allopregnanolone in humans: gender, age and endocrine influences. J. Clin. Endocrinol. Metab. 83, 2099-2103. doi: 10.1210/jc. 83.6.2099

Ghoumari, A. M., Ibanez, C., El-Etr, M., Leclerc, P., Eychenne, B., O’malley, B. W., et al. (2003). Progesterone and its metabolites increase myelin basic protein expression in organotypic slice cultures of rat cerebellum. J. Neurochem. 86, 848859. doi: 10.1046/j.1471-4159.2003.01881.x

Gillies, G. E., and Mcarthur, S. (2010). Estrogen actions in the brain and the basis for differential action in men and women: a case for sex-specific medicines. Pharmacol. Rev. 62, 155-198. doi: 10.1124/pr.109.002071

Goodkin, H. P., Yeh, J. L., and Kapur, J. (2005). Status epilepticus increases the intracellular accumulation of GABAA receptors. J. Neurosci. 25, 5511-5520. doi: 10.1523/jneurosci.0900-05.2005

Grant, K. A., Helms, C. M., Rogers, L. S., and Purdy, R. H. (2008). Neuroactive steroid stereospecificity of ethanol-like discriminative stimulus effects in monkeys. J. Pharmacol. Exp. Ther. 326, 354-361. doi: 10.1124/jpet.108.137315

Griffin, L. D., and Mellon, S. H. (2001). Biosynthesis of the neurosteroid 3 alphahydroxy-4-pregnen-20-one ( 3 alpha hp), a specific inhibitor of FSH release. Endocrinology 142, 4617-4622. doi: 10.1210/en.142.11.4617

Griffin, L. D., Gong, W., Verot, L., and Mellon, S. H. (2004). Niemann-Pick type $\mathrm{C}$ disease involves disrupted neurosteroidogenesis and responds to allopregnanolone. Nat. Med. 10, 704-711. doi: 10.1038/nm1073

Haas, H., and Panula, P. (2003). The role of histamine and the tuberomamillary nucleus in the nervous system. Nat. Rev. Neurosci. 4, 121-130. doi: 10. 1038/nrn1034

Hafner, V., Czock, D., Burhenne, J., Riedel, K. D., Bommer, J., Mikus, G., et al. (2010). Pharmacokinetics of sulfobutylether-beta-cyclodextrin and voriconazole in patients with end-stage renal failure during treatment with two hemodialysis systems and hemodiafiltration. Antimicrob. Agents Chemother. 54, 2596-2602. doi: 10.1128/aac.01540-09 
He, J., Evans, C. O., Hoffman, S. W., Oyesiku, N. M., and Stein, D. G. (2004a). Progesterone and allopregnanolone reduce inflammatory cytokines after traumatic brain injury. Exp. Neurol. 189, 404-412. doi: 10.1016/j.expneurol.2004. 06.008

He, J., Hoffman, S. W., and Stein, D. G. (2004b). Allopregnanolone, a progesterone metabolite, enhances behavioral recovery and decreases neuronal loss after traumatic brain injury. Restor. Neurol. Neurosci. 22, 19-31.

Hosie, A. M., Wilkins, M. E., Da Silva, H. M., and Smart, T. G. (2006). Endogenous neurosteroids regulate GABAA receptors through two discrete transmembrane sites. Nature 444, 486-489. doi: 10.1038/nature05324

Hutson, C. B., Lazo, C. R., Mortazavi, F., Giza, C. C., Hovda, D., and Chesselet, M. F. (2011). Traumatic brain injury in adult rats causes progressive nigrostriatal dopaminergic cell loss and enhanced vulnerability to the pesticide paraquat. $J$. Neurotrauma 28, 1783-1801. doi: 10.1089/neu.2010.1723

Irwin, R. W., and Brinton, R. D. (2014). Allopregnanolone as regenerative therapeutic for Alzheimer's disease: translational development and clinical promise. Prog. Neurobiol. 113, 40-55. doi: 10.1016/j.pneurobio.2013.08.004

Irwin, R. W., Solinsky, C. M., Chen, S., and Brinton, R. D. (2013). Preclinical safety and efficacy of allopregnanolone for Alzheimer's disease therapy. Soc. Neurosci. Annu. Meet. Abstracts.

Irwin, R. W., Wang, J. M., Chen, S., and Brinton, R. D. (2011). Neuroregenerative mechanisms of allopregnanolone in Alzheimer's disease. Front. Endocrinol. (Lausanne) 2:117. doi: 10.3389/fendo.2011.00117

Jakobsson, T., Treuter, E., Gustafsson, J. A., and Steffensen, K. R. (2012). Liver X receptor biology and pharmacology: new pathways, challenges and opportunities. Trends Pharmacol. Sci. 33, 394-404. doi: 10.1016/j.tips.2012.03.013

Jiang, Q., Lee, C. Y., Mandrekar, S., Wilkinson, B., Cramer, P., Zelcer, N., et al. (2008). ApoE promotes the proteolytic degradation of Abeta. Neuron 58, 681693. doi: 10.1016/j.neuron.2008.04.010

Jin, K., Peel, A. L., Mao, X. O., Xie, L., Cottrell, B. A., Henshall, D. C., et al. (2004). Increased hippocampal neurogenesis in Alzheimer's disease. Proc. Natl. Acad. Sci. US A 101, 343-347. doi: 10.1073/pnas.263479410

Johnson, V. E., Stewart, W., and Smith, D. H. (2012). Widespread tau and amyloidbeta pathology many years after a single traumatic brain injury in humans. Brain Pathol. 22, 142-149. doi: 10.1111/j.1750-3639.2011.00513.x

Jovanovic, J. N., Thomas, P., Kittler, J. T., Smart, T. G., and Moss, S. J. (2004). Brain-derived neurotrophic factor modulates fast synaptic inhibition by regulating $\mathrm{GABA}(\mathrm{A})$ receptor phosphorylation, activity and cell-surface stability. $J$. Neurosci. 24, 522-530. doi: 10.1523/jneurosci.3606-03.2004

Juptner, M., and Hiemke, C. (1990). Sex differences in GABAA receptor binding in rat brain measured by an improved in vitro binding assay. Exp. Brain Res. 81, 297-302. doi: 10.1007/bf00228119

Kaminski, R. M., Livingood, M. R., and Rogawski, M. A. (2004). Allopregnanolone analogs that positively modulate GABA receptors protect against partial seizures induced by 6-Hz electrical stimulation in mice. Epilepsia 45, 864-867. doi: 10 . 1111/j.0013-9580.2004.04504.x

Kask, K., Backstrom, T., Lundgren, P., and Sundstrom Poromaa, I. (2009). Allopregnanolone has no effect on startle response and prepulse inhibition of startle response in patients with premenstrual dysphoric disorder or healthy controls. Pharmacol. Biochem. Behav. 92, 608-613. doi: 10.1016/j.pbb.2009. 02.014

Kask, K., Backstrom, T., Nilsson, L. G., and Sundstrom-Poromaa, I. (2008). Allopregnanolone impairs episodic memory in healthy women. Psychopharmacology (Berl) 199, 161-168. doi: 10.1007/s00213-008-1150-7

Kelley, M. H., Kuroiwa, M., Taguchi, N., and Herson, P. S. (2011). Sex difference in sensitivity to allopregnanolone neuroprotection in mice correlates with effect on spontaneous inhibitory post synaptic currents. Neuropharmacology 61, 724-729. doi: 10.1016/j.neuropharm.2011.05.017

Kerrigan, J. F., Shields, W. D., Nelson, T. Y., Bluestone, D. L., Dodson, W. E., Bourgeois, B. F., et al. (2000). Ganaxolone for treating intractable infantile spasms: a multicenter, open-label, add-on trial. Epilepsy Res. 42, 133-139. doi: 10.1016/s0920-1211(00)00170-4

Kittler, J. T., Delmas, P., Jovanovic, J. N., Brown, D. A., Smart, T. G., and Moss, S. J. (2000). Constitutive endocytosis of GABAA receptors by an association with the adaptin AP2 complex modulates inhibitory synaptic currents in hippocampal neurons. J. Neurosci. 20, 7972-7977.

Koldamova, R., Fitz, N. F., and Lefterov, I. (2010). The role of ATP-binding cassette transporter A1 in Alzheimer's disease and neurodegeneration. Biochim. Biophys. Acta 1801, 824-830. doi: 10.1016/j.bbalip.2010.02.010
Lancel, M. (1999). Role of GABAA receptors in the regulation of sleep: initial sleep responses to peripherally administered modulators and agonists. Sleep 22, 33-42.

Lazarov, O., and Marr, R. A. (2010). Neurogenesis and Alzheimer's disease: at the crossroads. Exp. Neurol. 223, 267-281. doi: 10.1016/j.expneurol.2009.08.009

Leduc, V., Jasmin-Belanger, S., and Poirier, J. (2010a). APOE and cholesterol homeostasis in Alzheimer's disease. Trends Mol. Med. 16, 469-477. doi: 10. 1016/j.molmed.2010.07.008

Leduc, V., Jasmin-Belanger, S., and Poirier, J. (2010b). APOE and cholesterol homeostasis in Alzheimer's disease. Trends Mol. Med. 16, 469-477. doi: 10. 1016/j.molmed.2010.07.008

Leonelli, E., Bianchi, R., Cavaletti, G., Caruso, D., Crippa, D., Garcia-Segura, L. M., et al. (2007). Progesterone and its derivatives are neuroprotective agents in experimental diabetic neuropathy: a multimodal analysis. Neuroscience 144, 1293-1304. doi: 10.1016/j.neuroscience.2006.11.014

Liu, J., Rone, M. B., and Papadopoulos, V. (2006). Protein-protein interactions mediate mitochondrial cholesterol transport and steroid biosynthesis. J. Biol. Chem. 281, 38879-38893. doi: 10.1074/jbc.M608820200

Liu, X., Wang, Q., Haydar, T. F., and Bordey, A. (2005). Nonsynaptic GABA signaling in postnatal subventricular zone controls proliferation of GFAP-expressing progenitors. Nat. Neurosci. 8, 1179-1187. doi: 10.1038/nn1522

Lo, A. W., Ho, C., Cummings, J., and Kosik, K. S. (2014). Parallel discovery of Alzheimer's therapeutics. Sci. Transl. Med. 6:241 cm245. doi: 10.1126/ scitranslmed. 3008228

Lovick, T. A. (2008). GABA in the female brain-oestrous cycle-related changes in GABAergic function in the periaqueductal grey matter. Pharmacol. Biochem. Behav. 90, 43-50. doi: 10.1016/j.pbb.2007.12.014

Luchetti, S., Bossers, K., Frajese, G. V., and Swaab, D. F. (2010). Neurosteroid biosynthetic pathway changes in substantia nigra and caudate nucleus in Parkinson's disease. Brain Pathol. 20, 945-951. doi: 10.1111/j.1750-3639.2010. 00396.x

Luchetti, S., Huitinga, I., and Swaab, D. F. (2011). Neurosteroid and GABA-A receptor alterations in Alzheimer's disease, Parkinson's disease and multiple sclerosis. Neuroscience 191, 6-21. doi: 10.1016/j.neuroscience.2011.04.010

Luisi, S., Petraglia, F., Benedetto, C., Nappi, R. E., Bernardi, F., Fadalti, M., et al. (2000). Serum allopregnanolone levels in pregnant women: changes during pregnancy, at delivery and in hypertensive patients. J. Clin. Endocrinol. Metab. 85, 2429-2433. doi: 10.1210/jc.85.7.2429

Luke, D. R., Tomaszewski, K., Damle, B., and Schlamm, H. T. (2010). Review of the basic and clinical pharmacology of sulfobutylether-beta-cyclodextrin (SBECD). J. Pharm. Sci. 99, 3291-3301. doi: 10.1002/jps.22109

MacNevin, C. J., Atif, F., Sayeed, I., Stein, D. G., and Liotta, D. C. (2009). Development and screening of water-soluble analogues of progesterone and allopregnanolone in models of brain injury. J. Med. Chem. 52, 6012-6023. doi: $10.1021 /$ jm $900712 \mathrm{n}$

Mahley, R. W. (1988). Apolipoprotein E: cholesterol transport protein with expanding role in cell biology. Science 240, 622-630. doi: 10.1126/science.3283935

Malberg, J. E., Eisch, A. J., Nestler, E. J., and Duman, R. S. (2000). Chronic antidepressant treatment increases neurogenesis in adult rat hippocampus. $J$. Neurosci. 20, 9104-9110.

Marx, C. E., Trost, W. T., Shampine, L. J., Stevens, R. D., Hulette, C. M., Steffens, D. C., et al. (2006). The neurosteroid allopregnanolone is reduced in prefrontal cortex in Alzheimer's disease. Biol. Psychiatry 60, 1287-1294. doi: 10.1016/j. biopsych.2006.06.017

Mayo, W., Lemaire, V., Malaterre, J., Rodriguez, J. J., Cayre, M., Stewart, M. G., et al. (2005). Pregnenolone sulfate enhances neurogenesis and PSA-NCAM in young and aged hippocampus. Neurobiol. Aging 26, 103-114. doi: 10.1016/j. neurobiolaging.2004.03.013

Melcangi, R. C., Froelichsthal, P., Martini, L., and Vescovi, A. L. (1996). Steroid metabolizing enzymes in pluripotential progenitor central nervous system cells: effect of differentiation and maturation. Neuroscience 72, 467-475. doi: 10 . 1016/0306-4522(95)00522-6

Melcangi, R. C., Magnaghi, V., Cavarretta, I., Zucchi, I., Bovolin, P., D’urso, D., et al. (1999). Progesterone derivatives are able to influence peripheral myelin protein 22 and P0 gene expression: possible mechanisms of action. J. Neurosci. Res. 56, 349-357. doi: 10.1002/(sici)1097-4547(19990515)56:4<349::aid-jnr3>3.3. $\mathrm{co} ; 2-8$

Meldrum, B. S., and Rogawski, M. A. (2007). Molecular targets for antiepileptic drug development. Neurotherapeutics 4, 18-61. doi: 10.1016/j.nurt.2006.11.010 
Mellon, S. H. (2007). Neurosteroid regulation of central nervous system development. Pharmacol. Ther. 116, 107-124. doi: 10.1016/j.pharmthera.2007.04.011

Mellon, S. H., Gong, W., and Schonemann, M. D. (2008). Endogenous and synthetic neurosteroids in treatment of Niemann-Pick Type C disease. Brain Res. Rev. 57, 410-420. doi: 10.1016/j.brainresrev.2007.05.012

Mellon, S. H., Griffin, L. D., and Compagnone, N. A. (2001). Biosynthesis and action of neurosteroids. Brain Res. Brain Res. Rev. 37, 3-12. doi: 10.1016/s01650173(01)00109-6

Mellon, S. H., and Vaudry, H. (2001). Biosynthesis of neurosteroids and regulation of their synthesis. Int. Rev. Neurobiol. 46, 33-78. doi: 10.1016/s0074$7742(01) 46058-2$

Meyer, L., Venard, C., Schaeffer, V., Patte-Mensah, C., and Mensah-Nyagan, A. G. (2008). The biological activity of 3alpha-hydroxysteroid oxido-reductase in the spinal cord regulates thermal and mechanical pain thresholds after sciatic nerve injury. Neurobiol. Dis. 30, 30-41. doi: 10.1016/j.nbd.2007.12.001

Mueller, B. K., Mueller, R., and Schoemaker, H. (2009). Stimulating neuroregeneration as a therapeutic drug approach for traumatic brain injury. Br. J. Pharmacol. 157, 675-685. doi: 10.1111/j.1476-5381.2009.00220.x

Mullard, A. (2012). Sting of Alzheimer's failures offset by upcoming prevention trials. Nat. Rev. Drug Discov. 11, 657-660. doi: 10.1038/nrd3842

Mullard, A. (2013). 2012 FDA drug approvals. Nat. Rev. Drug Discov. 12, 87-90. doi: $10.1038 / \mathrm{nrd} 3946$

Naylor, J. C., Kilts, J. D., Hulette, C. M., Steffens, D. C., Blazer, D. G., Ervin, J. F., et al. (2010). Allopregnanolone levels are reduced in temporal cortex in patients with Alzheimer's disease compared to cognitively intact control subjects. Biochim. Biophys. Acta 1801, 951-959. doi: 10.1016/j.bbalip.2010. 05.006

Nelson, L. E., Guo, T. Z., Lu, J., Saper, C. B., Franks, N. P., and Maze, M. (2002). The sedative component of anesthesia is mediated by $\operatorname{GABA}(\mathrm{A})$ receptors in an endogenous sleep pathway. Nat. Neurosci. 5, 979-984. doi: 10.1038/ nn913

Noorbakhsh, F., Baker, G. B., and Power, C. (2014). Allopregnanolone and neuroinflammation: a focus on multiple sclerosis. Front. Cell. Neurosci. 8:134. doi: 10. 3389/fncel.2014.00134

Noorbakhsh, F., Ellestad, K. K., Maingat, F., Warren, K. G., Han, M. H., Steinman, L., et al. (2011). Impaired neurosteroid synthesis in multiple sclerosis. Brain 134, 2703-2721. doi: 10.1093/brain/awr200

Overstreet Wadiche, L., Bromberg, D. A., Bensen, A. L., and Westbrook, G. L. (2005). GABAergic signaling to newborn neurons in dentate gyrus. J. Neurophysiol. 94, 4528-4532. doi: 10.1152/jn.00633.2005

Owens, D. F., and Kriegstein, A. R. (2002). Is there more to GABA than synaptic inhibition? Nat. Rev. Neurosci. 3, 715-727. doi: 10.1038/nrn919

Palmer, T. D., Schwartz, P. H., Taupin, P., Kaspar, B., Stein, S. A., and Gage, F. H. (2001). Cell culture. Progenitor cells from human brain after death. Nature 411, 42-43. doi: 10.1038/35075141

Patte-Mensah, C., Kibaly, C., and Mensah-Nyagan, A. G. (2005). Substance P inhibits progesterone conversion to neuroactive metabolites in spinal sensory circuit: a potential component of nociception. Proc. Natl. Acad. Sci. U S A 102, 9044-9049. doi: 10.1073/pnas.0502968102

Paul, S. M., and Purdy, R. H. (1992). Neuroactive steroids. FASEB J. 6, 2311-2322.

Perry, R. J., Watson, P., and Hodges, J. R. (2000). The nature and staging of attention dysfunction in early (minimal and mild) Alzheimer's disease: relationship to episodic and semantic memory impairment. Neuropsychologia 38, 252-271. doi: 10.1016/s0028-3932(99)00079-2

Pfeifer, M., Boncristiano, S., Bondolfi, L., Stalder, A., Deller, T., Staufenbiel, M., et al. (2002). Cerebral hemorrhage after passive anti-Abeta immunotherapy. Science 298:1379. doi: 10.1126/science.1078259

Pierobon, P., Tino, A., Minei, R., and Marino, G. (2004). Different roles of GABA and glycine in the modulation of chemosensory responses in Hydra vulgaris (Cnidaria, Hydrozoa). Dev. Hydrobiologia 178, 59-66. doi: 10.1007/978-1-40202762-8_7

Racke, M. M., Boone, L. I., Hepburn, D. L., Parsadainian, M., Bryan, M. T., Ness, D. K., et al. (2005). Exacerbation of cerebral amyloid angiopathyassociated microhemorrhage in amyloid precursor protein transgenic mice by immunotherapy is dependent on antibody recognition of deposited forms of amyloid beta. J. Neurosci. 25, 629-636. doi: 10.1523/jneurosci.433704.2005

Riddell, D. R., Zhou, H., Comery, T. A., Kouranova, E., Lo, C. F., Warwick, H. K., et al. (2007). The LXR agonist TO901317 selectively lowers hippocampal
Abeta42 and improves memory in the Tg2576 mouse model of Alzheimer's disease. Mol. Cell. Neurosci. 34, 621-628. doi: 10.1016/j.mcn.2007.01.011

Rodriguez, J. J., Jones, V. C., and Verkhratsky, A. (2009). Impaired cell proliferation in the subventricular zone in an Alzheimer's disease model. Neuroreport 20, 907912. doi: $10.1097 /$ wnr.0b013e32832be77d

Rodriguez, J. J., Jones, V. C., Tabuchi, M., Allan, S. M., Knight, E. M., Laferla, F. M., et al. (2008). Impaired adult neurogenesis in the dentate gyrus of a triple transgenic mouse model of Alzheimer's disease. PLoS One 3:e2935. doi: 10. 1371/journal.pone.0002935

Rogawski, M. A., Loya, C. M., Reddy, K., Zolkowska, D., and Lossin, C. (2013). Neuroactive steroids for the treatment of status epilepticus. Epilepsia 54(Suppl. 6), 93-98. doi: 10.1111/epi.12289

Rouge-Pont, F., Mayo, W., Marinelli, M., Gingras, M., Le Moal, M., and Piazza, P. V. (2002). The neurosteroid allopregnanolone increases dopamine release and dopaminergic response to morphine in the rat nucleus accumbens. Eur. J. Neurosci. 16, 169-173. doi: 10.1046/j.1460-9568.2002. 02084.x

Rupprecht, R., Papadopoulos, V., Rammes, G., Baghai, T. C., Fan, J., Akula, N., et al. (2010). Translocator protein $(18 \mathrm{kDa})(\mathrm{TSPO})$ as a therapeutic target for neurological and psychiatric disorders. Nat. Rev. Drug Discov. 9, 971-988. doi: $10.1038 / \mathrm{nrd} 3295$

Salloway, S., Sperling, R., Gilman, S., Fox, N. C., Blennow, K., Raskind, M., et al. (2009). A phase 2 multiple ascending dose trial of bapineuzumab in mild to moderate Alzheimer disease. Neurology 73, 2061-2070. doi: 10.1212/wnl. 0b013e3181c67808

Saredi, S., Patte-Mensah, C., Melcangi, R. C., and Mensah-Nyagan, A. G. (2005). Effect of streptozotocin-induced diabetes on the gene expression and biological activity of 3beta-hydroxysteroid dehydrogenase in the rat spinal cord. Neuroscience 135, 869-877. doi: 10.1016/j.neuroscience.2005.06.033

Sayeed, I., Parvez, S., Wali, B., Siemen, D., and Stein, D. G. (2009). Direct inhibition of the mitochondrial permeability transition pore: a possible mechanism for better neuroprotective effects of allopregnanolone over progesterone. Brain Res. 1263, 165-173. doi: 10.1016/j.brainres.2009.01.045

Schneider, L. S. (2014). Rethinking the food and drug administration's 2013 guidance on developing drugs for early-stage Alzheimer's disease. Alzheimers Dement. 10, 247-250. doi: 10.1016/j.jalz.2013.12.002

Schultz, J. R., Tu, H., Luk, A., Repa, J. J., Medina, J. C., Li, L., et al. (2000). Role of LXRs in control of lipogenesis. Genes Dev. 14, 2831-2838. doi: 10.1101/gad. 850400

Schumacher, M., Guennoun, R., Robert, F., Carelli, C., Gago, N., Ghoumari, A., et al. (2004). Local synthesis and dual actions of progesterone in the nervous system: neuroprotection and myelination. Growth Horm. IGF Res. 14(Suppl. A), S18-S33. doi: 10.1016/j.ghir.2004.03.007

Schumacher, M., Hussain, R., Gago, N., Oudinet, J. P., Mattern, C., and Ghoumari, A. M. (2012). Progesterone synthesis in the nervous system: implications for myelination and myelin repair. Front. Neurosci. 6:10. doi: 10.3389/fnins.2012. 00010

Schumacher, M., Mattern, C., Ghoumari, A., Oudinet, J. P., Liere, P., Labombarda, F., et al. (2014). Revisiting the roles of progesterone and allopregnanolone in the nervous system: resurgence of the progesterone receptors. Prog. Neurobiol. 113, 6-39. doi: 10.1016/j.pneurobio.2013.09.004

Shenoy, S. D., Spencer, T. A., Mercer-Haines, N. A., Alipour, M., Gargano, M. D., Runge-Morris, M., et al. (2004). CYP3A induction by liver x receptor ligands in primary cultured rat and mouse hepatocytes is mediated by the pregnane X receptor. Drug Metab. Dispos. 32, 66-71. doi: 10.1124/dmd. 32.1.66

Singh, C., Liu, L., Wang, J. M., Irwin, R. W., Yao, J., Chen, S., et al. (2012). Allopregnanolone restores hippocampal-dependent learning and memory and neural progenitor survival in aging $3 \mathrm{xTgAD}$ and nonTg mice. Neurobiol. Aging 33, 1493-1506. doi: 10.1016/j.neurobiolaging.2011.06.008

Sipila, S., Huttu, K., Voipio, J., and Kaila, K. (2004). GABA uptake via GABA transporter-1 modulates GABAergic transmission in the immature hippocampus. J. Neurosci. 24, 5877-5880. doi: 10.1523/jneurosci.1287-04.2004

Spalding, K. L., Bergmann, O., Alkass, K., Bernard, S., Salehpour, M., Huttner, H. B., et al. (2013). Dynamics of hippocampal neurogenesis in adult humans. Cell 153, 1219-1227. doi: 10.1016/j.cell.2013.05.002

Sperling, R. A., Aisen, P. S., Beckett, L. A., Bennett, D. A., Craft, S., Fagan, A. M., et al. (2011a). Toward defining the preclinical stages of Alzheimer's disease: recommendations from the national institute on aging-Alzheimer's 
association workgroups on diagnostic guidelines for Alzheimer's disease. Alzheimers Dement. 7, 280-292. doi: 10.1016/j.jalz.2011.03.003

Sperling, R. A., Jack, C. R. Jr., Black, S. E., Frosch, M. P., Greenberg, S. M., Hyman, B. T., et al. (2011b). Amyloid-related imaging abnormalities in amyloid-modifying therapeutic trials: recommendations from the Alzheimer's association research roundtable workgroup. Alzheimers Dement. 7, 367-385. doi: 10.1016/j.jalz.2011.05.2351

Sperling, R., Salloway, S., Brooks, D. J., Tampieri, D., Barakos, J., Fox, N. C., et al. (2012). Amyloid-related imaging abnormalities in patients with Alzheimer's disease treated with bapineuzumab: a retrospective analysis. Lancet Neurol. 11, 241-249. doi: 10.1016/j.jalz.2012.05.1624

Steinmetz, K. L., and Spack, E. G. (2009). The basics of preclinical drug development for neurodegenerative disease indications. BMC Neurol. 9(Suppl. 1):S2. doi: 10.1186/1471-2377-9-s1-s2

Sun, Y., Yao, J., Kim, T. W., and Tall, A. R. (2003). Expression of liver X receptor target genes decreases cellular amyloid beta peptide secretion. J. Biol. Chem. 278, 27688-27694. doi: 10.1074/jbc.m300760200

Terwel, D., Steffensen, K. R., Verghese, P. B., Kummer, M. P., Gustafsson, J. A., Holtzman, D. M., et al. (2011). Critical role of astroglial apolipoprotein E and liver X receptor-alpha expression for microglial Abeta phagocytosis. J. Neurosci. 31, 7049-7059. doi: 10.1523/jneurosci.6546-10.2011

Timby, E., Balgard, M., Nyberg, S., Spigset, O., Andersson, A., PorankiewiczAsplund, J., et al. (2006). Pharmacokinetic and behavioral effects of allopregnanolone in healthy women. Psychopharmacology (Berl) 186, 414-424. doi: 10 . 1007/s00213-005-0148-7

Turkmen, S., Lofgren, M., Birzniece, V., Backstrom, T., and Johansson, I. M. (2006). Tolerance development to Morris water maze test impairments induced by acute allopregnanolone. Neuroscience 139, 651-659. doi: 10.1016/j.neuroscience.2005. 12.031

Uzunova, V., Sampson, L., and Uzunov, D. P. (2006). Relevance of endogenous 3alpha-reduced neurosteroids to depression and antidepressant action. Psychopharmacology (Berl) 186, 351-361. doi: 10.1007/s00213-005-0201-6

Uzunova, V., Wrynn, A. S., Kinnunen, A., Ceci, M., Kohler, C., and Uzunov, D. P. (2004). Chronic antidepressants reverse cerebrocortical allopregnanolone decline in the olfactory-bulbectomized rat. Eur. J. Pharmacol. 486, 31-34. doi: 10.1016/j.ejphar.2003.12.002

van Broekhoven, F., Backstrom, T., Van Luijtelaar, G., Buitelaar, J. K., Smits, P., and Verkes, R. J. (2007). Effects of allopregnanolone on sedation in men and in women on oral contraceptives. Psychoneuroendocrinology 32, 555-564. doi: 10. 1016/j.psyneuen.2007.03.009

Van Steveninck, A. L., Mandema, J. W., Tuk, B., Van Dijk, J. G., Schoemaker, H. C., Danhof, M., et al. (1993). A comparison of the concentration-effect relationships of midazolam for EEG-derived parameters and saccadic peak velocity. Br. J. Clin. Pharmacol. 36, 109-115. doi: 10.1111/j.1365-2125.1993. tb04205.x

VanLandingham, J. W., Cekic, M., Cutler, S., Hoffman, S. W., and Stein, D. G. (2007). Neurosteroids reduce inflammation after TBI through CD55 induction. Neurosci. Lett. 425, 94-98. doi: 10.1016/j.neulet.2007.08.045

Voss, H. U., Uluc, A. M., Dyke, J. P., Watts, R., Kobylarz, E. J., Mccandliss, B. D., et al. (2006). Possible axonal regrowth in late recovery from the minimally conscious state. J. Clin. Invest. 116, 2005-2011. doi: 10.1172/jci27021

Wang, J. M., and Brinton, R. D. (2008). Allopregnanolone-induced rise in intracellular calcium in embryonic hippocampal neurons parallels their proliferative potential. BMC Neurosci. 9(Suppl. 2):S11. doi: 10.1186/1471-2202-9-s2-s11

Wang, J. M., Irwin, R. W., Liu, L., Chen, S., and Brinton, R. D. (2007). Regeneration in a degenerating brain: potential of allopregnanolone as a neuroregenerative agent. Curr. Alzheimer Res. 4, 510-517. doi: 10.2174/156720507783018262

Wang, J. M., Johnston, P. B., Ball, B. G., and Brinton, R. D. (2005). The neurosteroid allopregnanolone promotes proliferation of rodent and human neural progenitor cells and regulates cell-cycle gene and protein expression. J. Neurosci. 25, 4706-4718. doi: 10.1523/jneurosci.4520-04.2005

Wang, J. M., Singh, C., Liu, L., Irwin, R. W., Chen, S., Chung, E. J., et al. (2010). Allopregnanolone reverses neurogenic and cognitive deficits in mouse model of Alzheimer's disease. Proc. Natl. Acad. Sci. U S A 107, 6498-6503. doi: 10. 1073/pnas. 1006236107
Walker, T. L., Turnbull, G. W., Mackay, E. W., Hannan, A. J., and Bartlett, P. F. (2011). The latent stem cell population is retained in the hippocampus of transgenic Huntington's disease mice but not wild-type mice. PLoS One 6:e18153. doi: 10.1371/journal.pone.0018153

Weill-Engerer, S., David, J. P., Sazdovitch, V., Liere, P., Eychenne, B., Pianos, A., et al. (2002). Neurosteroid quantification in human brain regions: comparison between Alzheimer's and nondemented patients. J. Clin. Endocrinol. Metab. 87, 5138-5143. doi: 10.1210/jc.2002-020878

Whitwell, J. L., Przybelski, S. A., Weigand, S. D., Knopman, D. S., Boeve, B. F., Petersen, R. C., et al. (2007). 3D maps from multiple MRI illustrate changing atrophy patterns as subjects progress from mild cognitive impairment to Alzheimer's disease. Brain 130, 1777-1786. doi: 10.1093/brain/ awm 112

Whitney, K. D., Watson, M. A., Collins, J. L., Benson, W. G., Stone, T. M., Numerick, M. J., et al. (2002). Regulation of cholesterol homeostasis by the liver $\mathrm{X}$ receptors in the central nervous system. Mol. Endocrinol. 16, 1378-1385. doi: 10.1210/me. 16.6.1378

Xiong, H., Callaghan, D., Jones, A., Walker, D. G., Lue, L. F., Beach, T. G., et al. (2008). Cholesterol retention in Alzheimer's brain is responsible for high betaand gamma-secretase activities and Abeta production. Neurobiol. Dis. 29, 422437. doi: $10.1016 /$ j.nbd.2007.10.005

Yang, S. Y., He, X. Y., and Schulz, H. (2005). Multiple functions of type 10 17betahydroxysteroid dehydrogenase. Trends Endocrinol. Metab. 16, 167-175. doi: 10. 1016/j.tem.2005.03.006

Yang, Y., Varvel, N. H., Lamb, B. T., and Herrup, K. (2006). Ectopic cell cycle events link human Alzheimer's disease and amyloid precursor protein transgenic mouse models. J. Neurosci. 26, 775-784. doi: 10.1523/jneurosci.370705.2006

Zampieri, S., Mellon, S. H., Butters, T. D., Nevyjel, M., Covey, D. F., Bembi, B., et al. (2009). Oxidative stress in NPC1 deficient cells: protective effect of allopregnanolone. J. Cell. Mol. Med. 13, 3786-3796. doi: 10.1111/j.1582-4934. 2008.00493.x

Zelcer, N., Khanlou, N., Clare, R., Jiang, Q., Reed-Geaghan, E. G., Landreth, G. E., et al. (2007). Attenuation of neuroinflammation and Alzheimer's disease pathology by liver x receptors. Proc. Natl. Acad. Sci. U S A 104, 10601-10606. doi: 10.1073/pnas.0701096104

Zhao, L., Morgan, T. E., Mao, Z., Lin, S., Cadenas, E., Finch, C. E., et al. (2012). Continuous versus cyclic progesterone exposure differentially regulates hippocampal gene expression and functional profiles. PLoS One 7:e31267. doi: 10. 1371/journal.pone. 0031267

Zhu, D., Wang, M. D., Backstrom, T., and Wahlstrom, G. (2001). Evaluation and comparison of the pharmacokinetic and pharmacodynamic properties of allopregnanolone and pregnanolone at induction of anaesthesia in the male rat. Br. J. Anaesth. 86, 403-412. doi: 10.1093/bja/86.3.403

Zolkowska, D., Dhir, A., Cooke, G. R., Wu, C., Zhu, L., Wulff, H., et al. (2013). Anticonvulsant activity of intravenous and intramuscular allopregnenalone. Epilepsy Curr. 13(Suppl. 1), 11 (Abst 1.023).

Zuccato, C., Valenza, M., and Cattaneo, E. (2010). Molecular mechanisms and potential therapeutical targets in Huntington's disease. Physiol. Rev. 90, 905-981. doi: 10.1152/physrev.00041.2009

Conflict of Interest Statement: Patents pending on allopregnanolone as a therapeutic for mild cognitive impairment and Alzheimer's disease.

Received: 30 April 2014; accepted: 04 July 2014; published online: 30 July 2014. Citation: Irwin RW, Solinsky CM and Brinton RD (2014) Frontiers in therapeutic development of allopregnanolone for Alzheimer's disease and other neurological disorders. Front. Cell. Neurosci. 8:203. doi: 10.3389/fncel.2014.00203

This article was submitted to the journal Frontiers in Cellular Neuroscience.

Copyright (๑) 2014 Irwin, Solinsky and Brinton. This is an open-access article distributed under the terms of the Creative Commons Attribution License (CC BY). The use, distribution or reproduction in other forums is permitted, provided the original author(s) or licensor are credited and that the original publication in this journal is cited, in accordance with accepted academic practice. No use, distribution or reproduction is permitted which does not comply with these terms. 